\title{
State of the Art Manufacturing and Engineering of Nanocellulose: A Review of Available Data and Industrial Applications
}

\author{
Serge Rebouillat ${ }^{1}$, Fernand Pla $^{2}$ \\ ${ }^{1}$ Currently with DuPont Int. Op. European Headquarter, Geneva, Switzerland; ${ }^{2}$ Laboratoire Réactions et Génie des Procédés, UMR \\ 7274, CNRS-Université de Lorraine, Nancy, France. \\ Email: sergereb@yahoo.com
}

Received January $18^{\text {th }}, 2013$; revised March $8^{\text {th }}, 2013$; accepted April $8^{\text {th }}, 2013$

Copyright (C 2013 Serge Rebouillat, Fernand Pla. This is an open access article distributed under the Creative Commons Attribution License, which permits unrestricted use, distribution, and reproduction in any medium, provided the original work is properly cited.

\begin{abstract}
This review provides a critical overview of the recent methods and processes developed for the production of cellulose nanoparticles with controlled morphology, structure and properties, and also sums up (1) the processes for the chemical modifications of these particles in order to prevent their re-aggregation during spray-drying procedures and to increase their reactivity, (2) the recent processes involved in the production of nanostructured biomaterials and composites. The structural and physical properties of those nanocelluloses, combined with their biodegradability, make them materials of choice in the very promising area of nanotechnology, likely subject to major commercial successes in the context of green chemistry. With a prospective and pioneering approach to the subject matter, various laboratories involved in this domain have developed bio-products now almost suitable to industrial applications; although some important steps remain to be overcome, those are worth been reviewed and supplemented. At this stage, several pilot units and demonstration plants have been built to improve, optimize and scale-up the processes developed at laboratory scale. Industrial reactors with suitable environment and modern control equipment are to be expected within that context. This review shall bring the suitable processing dimension that may be needed now, given the numerous reviews outlining the product potential attributes. An abundant literature database, close to 250 publications and patents, is provided, consolidating the various research and more practical angles.
\end{abstract}

Keywords: Nanocellulose; Processes; Production; Modifications; Biocomposites; Biomaterials; Engineering; Renewable; Bioadditives; Fibrous; Nanostructures; Green Chemistry

\section{Introduction}

Cellulose is an abundant natural material made from renewable and sustainable resources which is biodegradable, carbon neutral with low environmental, health and safety risks. It serves as the dominant reinforcing phase in plant structures. Owing to its low cost, biodegradability, low density and remarkable physical and mechanical properties, this material is subject of intensive research and development with the advent of nanotechnologies [1,2].

For quite a time it has been used as an ingredient in many industrial processes such as pulp and papermaking and the manufacture of synthetic textile fibers (e.g. organic and inorganic esters, alkyl, hydroxy alkyl and carboxyl alkyl ethers) which are used as key active components in coatings, optical films, foodstuffs, pharmaceu- tics, cosmetics, additives in building materials etc.

Moreover, given to the cellulose properties, mostly functionality, durability and uniformity, its use continues to grow in other domains such as the conversion of cellulose from energy dedicated crops into biofuels to produce cellulosic ethanol as an alternative fuel source. More recently, as further detailed in this review, the design of processes using cellulose nanoparticles $(\mathrm{CNs})$ for the generation of novel cellulose-based biomaterials and composites is a clear trend [1-7].

Cellulose is mainly produced in wood and plants such as hemp, flax, jute, ramie and cotton. It is also synthesized by algae, tunicates and bacteria [8-11]. Other abundant and largely unused sources of cellulose are agricultural residues (wastes and by-products) which are obtained at a low cost from a large variety of natural and re- 
newable materials. The physical and morphological structure of native cellulose in plant cell walls is very complex and heterogeneous, mainly because of its intimate association with the other components of the plants (polysaccharides, lignin...) [12].

Compared to cellulose extracted from wood, bacterial celluloses (BC) present better characteristics (higher purity, degree of polymerization, crystallinity, water content and mechanical stability). This is essentially due to their typical biosynthesis which yields nanofibers networks without the other components generally synthesized during wood or plants biosynthesis $[1,8]$.

Formed of repeating units (called cellobiose) resulting from connections of two anhydro-glucose rings joined via a $\beta-1,4$ glycosidic linkage, this linear homopolymer, depicted on Figure 1, is characterized by its extended and rather stiff rod-like conformation, its significant hydrophilicity and its functional pendant groups.

The secondary and the primary hydroxyl groups of the anhydro-glucose rings are the basis for extensive intraand intermolecular hydrogen bonding, allowing the formation of highly ordered three-dimensional crystal structures; therefore making cellulose a semi-rigid polymer which is not soluble neither in water nor in traditional organic solvents; additionally, no melting point.

Those multiple hydrogen bonds hold the chains firmly together side-by-side and form elementary microfibrils that have high tensile strength and confer an important rigidity to the cell walls. Depending on their origin, these microfibrils are generally constituted of fibrous structures, formed during the cellulose biosynthesis [13] also containing crystalline and noncrystalline domains located along their main axis. The noncrystalline domains are weak spots along the microfibrils which are aggregated in the parenchyma cell wall [12]. The later are larger macroscopic fibres with thickness around $20-50 \mu \mathrm{m}$ and length higher than $2000 \mu \mathrm{m}$, respectively. Cellulose properties are mainly related to this so-called supramolecular order and specific assembling.

In this review, four particle types will be considered to cover the cellulose-based particles. Those typically differ from each other as a function of the cellulose sourcing materials and the treatments involved in their production. Each particle type is distinct from one another; from the standpoints of size, aspect ratio, morphology, crystallinity, crystal structure, and end-use properties.

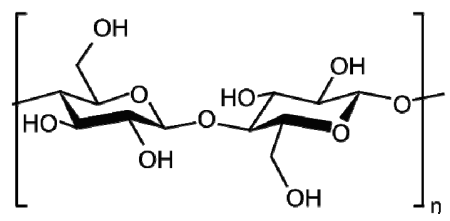

Figure 1. Chemical structure of cellulose.
Wood and plant cellulose fibers (bleached pulps) particles are the largest of the particle types.

Microcrystalline celluloses (MCCs) are generally described as purified and partially depolymerized cellulose particles with an average degree of polymerization between 200 and 450 [14]. They yield colloidal suspensions when dispersed in water. The stability of these suspensions depends on the dimensions of the dispersed particles, their size polydispersity and surface charges. MCCs are widely used as rheology control agents and in the pharmaceutical industry as excipients in the production of powders and tablets commonly known as fillers, binders, disintegrants and antiadherents [15].

Microfibrillated celluloses (MFCs) are generally obtained when cellulose fibres are submitted to high mechanical shearing forces. They are used as thickening agents in food and cosmetics industries.

Nanofibrillated celluloses (NFCs or nanofibrils) are produced when specific techniques facilitating fibrillation are incorporated in the mechanical refining of wood and plants pulps. They ideally consist of individual nanoparticles with a lateral dimension around $5 \mathrm{~nm}$. However, the production of fully degradable or biocompatible nanocomposites, containing NFC with high aspect ratio and diameters below $100 \mathrm{~nm}$, remains a challenging task because of the strong agglomeration tendency. The later can occur during drying of aqueous NFC suspensions or during compounding of NFC with hydrophobic polymers. This clustering is accompanied by an important decrease of the NFC aspect ratio and consequently results in a decrease or loss of some beneficial properties.

Cellulose nanocrystals (NCCs) are elongated rod-like or whisker shaped particles remaining after acid hydrolysis of wood and plants pulps, MCCs, MFCs or NFCs. They are considered today as a novel class of nanomaterials with many attracting properties [16]. Typically, NCCs are crystals with diameter in the range of 3 - 20 $\mathrm{nm}$ and length in the range of $100-600 \mathrm{~nm}$. Those dimensions and the crystallinity depend also on the source of cellulose used. Tunicate and bacterial cellulose yield larger whiskers, while cellulose from wood yields smaller structures [17,18]. Recently, Li et al. [19] reported the possibility of preparing nanospherical cellulose structures with diameters of several hundred nanometers from short-staple cotton by pre-swelling the fibers prior to the acid hydrolysis.

It should be noted that strong hydrogen bonding between the individual cellulose nanocrystals can promote re-aggregation during spray-drying procedures.

Indeed, compared to cellulose fibres, NCCs have, in addition to their nanoscale dimensions, many other advantages, such as, good stability, high surface area, interesting mechanical and optical properties which have 
promoted the attractiveness of this material in both fundamental research and application research. Therewith a huge amount of publications including several reviews and patents mainly devoted to physico-chemical studies of the structure, the morphology and the properties of cellulose nanofibrils and nanocrystals. Those studies clearly show the paramount potential of these materials for applications such as paints, varnishes and coatings, composites, films and barriers, adhesives, paper (retention and binder), thermosets, thermoplastics, reinforced biopolymers, natural and manufactured textiles, cosmetics and pharmaceuticals, medical and optical devices, viscosity modifiers and flow aids, hydrogels... Therefore, several pilot or demonstration plants of different capacities have been constructed around the world and are now producing CNs. Since these materials are new, there is a real need (i) to optimize and scale-up their production and to design plants and equipments of high capacity, (ii) to develop a manufacturing metrology infrastructure to control their properties and those of derived products (iii) to prospect on the economical feasibility of the corresponding processes [20]. The most known research \& development centers are located in North America (USA and Canada), Europe (Germany, France, Sweden, Finland, Switzerland, Norway and Austria), Japan, Israel and Argentina,

Table 1 [1-11,20-27] underlines the increasing interest for production of CNs, through these existing $\mathrm{R} \& \mathrm{D}$ centers.

This review study first provides a critical overview of the recent methods and processes developed for the production and the chemical transformations of $\mathrm{CNs}$ with tailored morphology and properties. A second part is devoted (i) to the processes developed for the production of nanocellulose-based neat materials and composites and (ii) to their corresponding applications.

From a process engineering standpoint, different prospective routes will be considered and discussed.

\section{Processes for the Production of Cellulose Nanoparticles (CNs)}

The production of CNs is generally carried out in two steps. The first stage consists of pretreatment of the raw material to obtain "purified" individual cellulosic fibers that can be further processed. Depending on the source of the raw material, different pre-treatments are applied. According to the desired size and morphology of the final CNs, the second stage (generally called "fibrillation") concerns the transformation of the individual cellulosic fibres into microfibrils, MFCs or NCCs. The main processes typically used for this transformation are mechanical treatment [21-24], acid hydrolysis [21-23,25] and enzymatic hydrolysis [21,23], which can be used separately or combined.

For example, in order to make disintegration of cellulosic fibers easier, enzymatic pretreatments followed by mechanical treatments were involved $[26,27]$. The pretreatments allow opening the structure of the material to facilitate access to the cellulose micro-structure during the second stage of the process. Thus, it is important to apply a sufficiently selective pretreatment which increases the access to the micro sites and still maintains a desired degree of polymerization. Figure 2 summarizes the methodology developed during the various stages of nanocellulose processing.

\subsection{First Stage}

In the case of wood, mostly used pretreatment processes are:

- Chemical processes as developed in the pulp and paper industry, to obtain bleached or chemically dissolved pulps by extracting lignin, hemicelluloses and other secondary products and via partial hydrolysis of cellulose. The different typical steps are: (i) cooking of wood chips in batch reactors (e.g. as per classical Kraft or sulfite processes), (ii) mechanical treatment

Table 1. Main centers possessing pilot or demonstration plants of different capacity [1-11,20-27].

\begin{tabular}{lcccc}
\hline Center & Country & Unit & Type of CN & Capacity \\
\hline FP Innovation & Canada & Pilot plant & NCC & $10 \mathrm{~kg} / \mathrm{week}$ \\
US Forest Service's Forest Products Laboratory & USA & Pilot plant & NCC & $35-50 \mathrm{~kg} / \mathrm{day}$ \\
Alberta Innovates_-Technology Futures & Canada & Pilot plant & NCC & $100 \mathrm{~kg} / \mathrm{week}$ \\
Celluforce Inc. & Canada & Demonstration plant & NCC & 1 tonne/day \\
Biovision Technologies Inc. & USA & Pilot plant & NCC & 4 tonnes/year \\
Inventia & Sweden & Demonstration plant & NFC & $100 \mathrm{~kg} / \mathrm{day}$ \\
The Us Forest Service & USA & Demonstration plant & NFC & $500 \mathrm{~kg} / \mathrm{day}$ \\
\hline
\end{tabular}




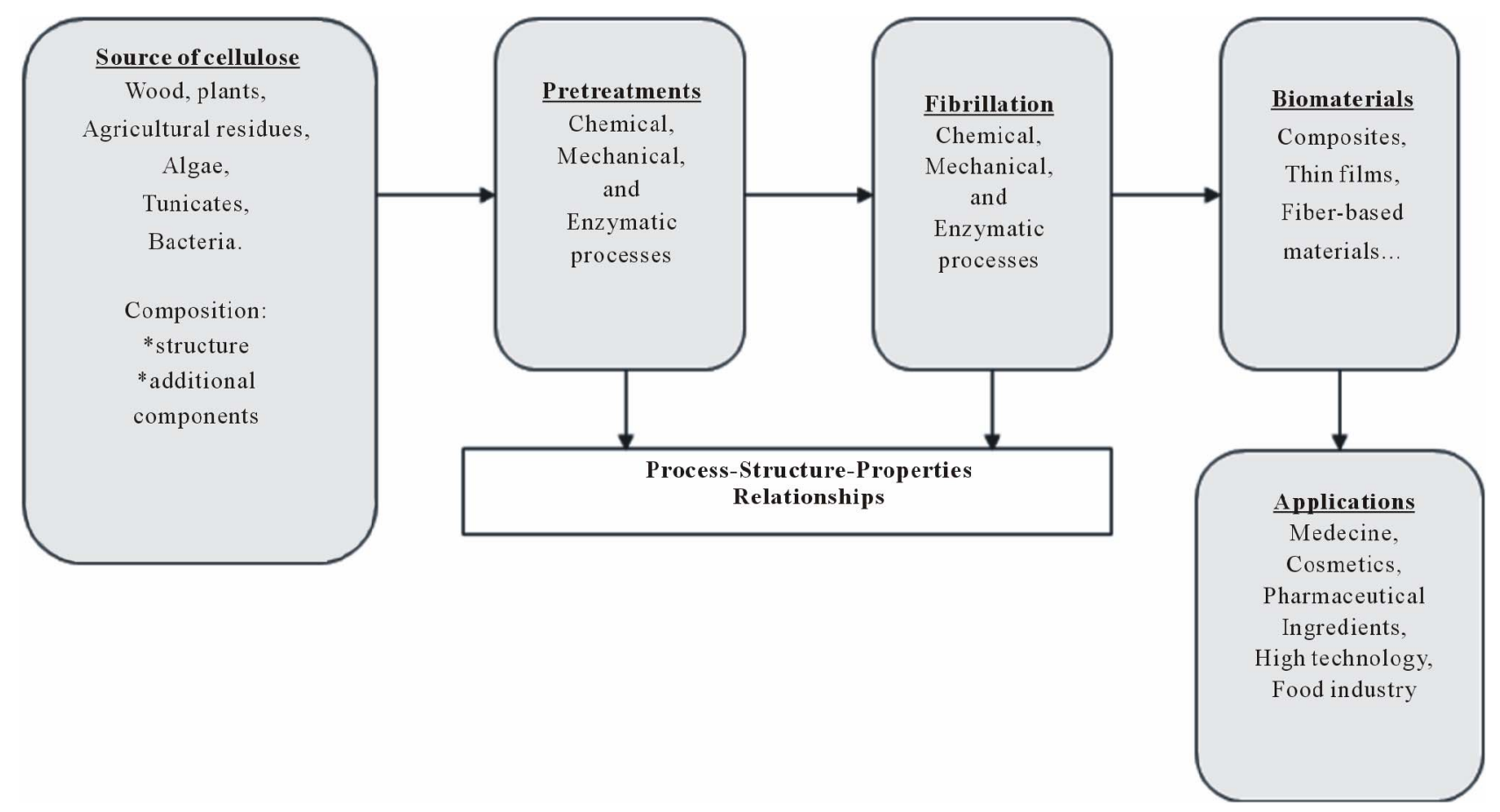

Figure 2. Flow chart depicting materials and steps during the processing of nanocellulose.

of the cooked chips to separate the fibers, (iii) bleaching of the resulting pulp to remove the residual lignin and other remaining by-products.

- Steam explosion process as described in Figure 3. The cellulosic biomass is pressurized for a short period of time in a batch reactor with water steam, and then explosively discharged to atmospheric pressure which results in a sudden disintegration changing the starting material into a fibrous dispersed solid which is then sequentially submitted to (i) extraction with water at $\sim 80^{\circ} \mathrm{C}$ for $\sim 1$ hour, using a fiber to water ratio of $\sim 1: 10$ followed by filtration and washing with water, (ii) extraction with $20 \mathrm{wt} \%$ sodium hydroxide at $80^{\circ} \mathrm{C}$ for $\sim 1 \mathrm{~h}$ using a fiber to liquor ratio of $1: 10$, (iii) bleaching, with a mixture of hydrogen peroxide and sodium hydroxide, in a stirred tank reactor, at $65^{\circ} \mathrm{C}$ for 2 hours. The bleached fibers are then diluted to $\sim 1 \%$ consistency and neutralized with sodium metabisulfite to decompose the residual hydrogen peroxide and stabilize the brightness.

This process has also been successfully applied to agricultural residues for the production of (i) nanofibrils of natural fibers [28], (ii) microfibrils [29], (iii) $M C C$ [30].

In the case of plants these two pretreatments are generally similar to those applied to wood. A wide variety of plants have been treated including cotton [31,32], bamboo [33], ramie [34], sisal [35,36], wheat straw [37-40] etc.

For tunicate the pretreatment involves the isolation of the mantel from the animal and the isolation of individual cellulose fibrils with the removal of the protein matrix.

The operating conditions of the pretreatments applied on different raw materials (e.g. tunicate [41-44], algae [45-50], bacteria cellulose [51,52] etc.) are well described in the literature.

These chemical processes have already been well developed, scaled-up and optimized. The resulting purified cellulose materials, mainly bleached and dissolved pulps, are commercially available and can be used during the following stage of CNs production.

\subsection{Second Stage}

\subsubsection{Acid Hydrolysis}

Acid hydrolysis processes currently employed consist of subjecting purified cellulosic material to strong acid under controlled operating conditions namely the nature of the acid, the acid concentration, the cellulose fibers to acid solution ratio, the temperature, the mixing rate, and the reaction time.

Several acids have been used for this type of production. Among them, hydrochloric and sulfuric acids are mostly used. Phosphoric [53-55] and maleic [56] acids have also been reported for such purpose.

With hydrochloric acid aggregation of CNs has been observed [57]. With sulfuric acid, surface charged sulfate esters are formed, promoting dispersion of the CNs in water and avoiding CNs aggregation [58], at the expense 


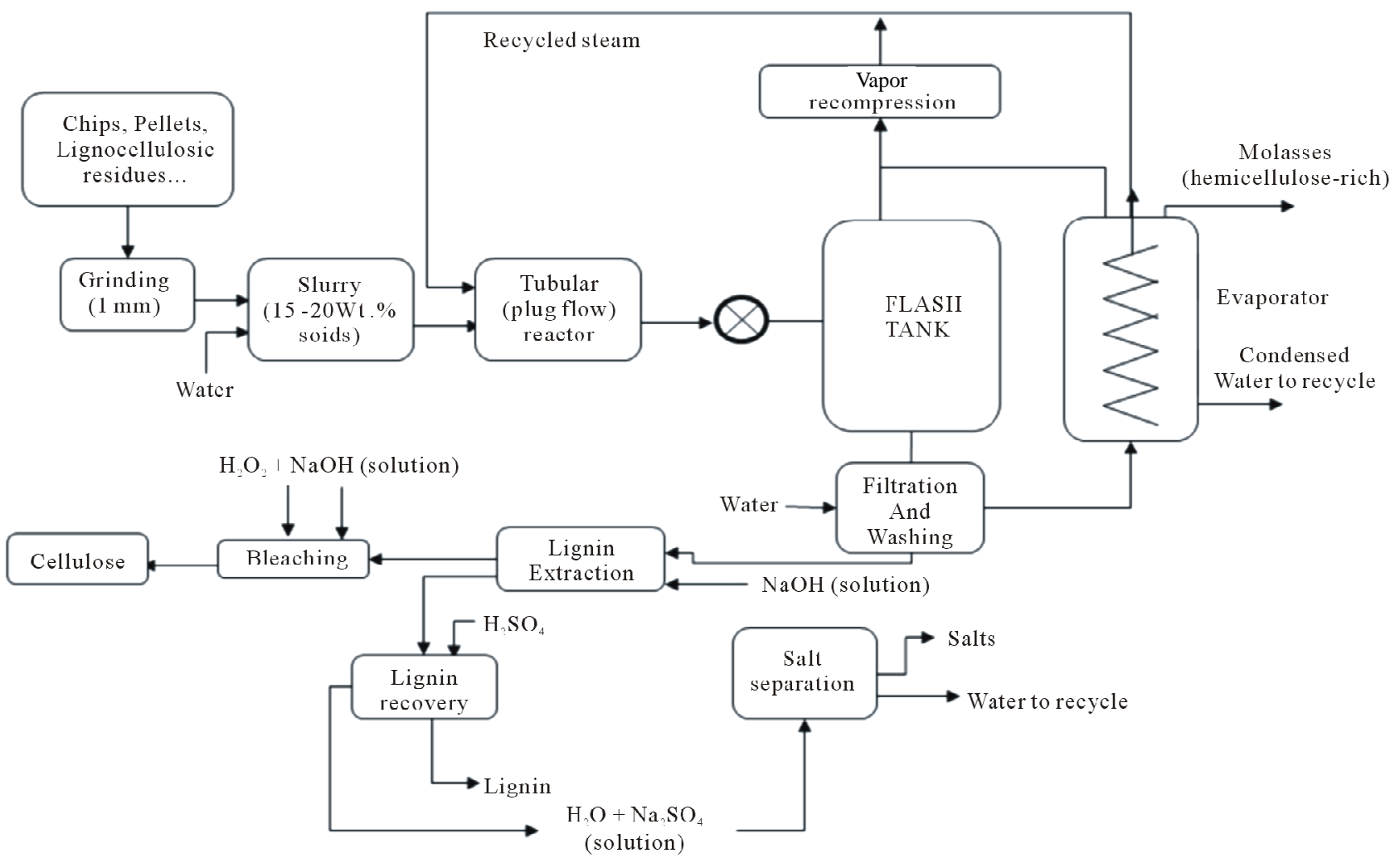

Figure 3. Process diagram for a typical aqueous/steam explosion system.

of the thermostability of the nanocrystals [59].

Combination of both sulfuric and hydrochloric acids during hydrolysis of CNs generates spherical nanoparticles with improved thermal stability due to less sulfate groups on their surface [60].

In general, sulfuric acid addition to a water fibers suspension is one of the most common method. At low concentration this type of acid, as well as chlorhydric acid, yields to MCCs or MFCs. Several methods, covered by patents, have been described in literature for the manufacture of MCC [61-63].

NCCs are obtained using concentrated sulfuric acid, at various temperatures and reaction times. The corresponding process operating conditions have been determined experimentally on different cellulosic materials [64-81]. In most cases, the sulfuric acid concentration is around $65 \%$ (wt), while the temperature ranges between $20^{\circ} \mathrm{C}$ and $70^{\circ} \mathrm{C}$ and the hydrolysis time varies from $30 \mathrm{~min}$. to overnight depending on the reaction temperature.

In general, the "purified" starting material is mixed into deionized water with a given amount of concentrated acid. After reacting for a set amount of time, the mixture is diluted with deionized water to quench the reaction. This mixture then undergoes a series of separation (centrifugation or filtration) and washing/rinsing steps followed by dialysis against deionized water to remove the remaining acid or neutralized salt. A final centrifuge separation or filtration step can be used to remove any larger agglomerates in the final cellulose nanoparticle suspension. Ultrasonic treatments can be used to facilitate dispersion of the crystalline cellulose in the suspension.

Most results show that longer hydrolysis time induces shorter nanocrystals with higher surface charge [64] and narrower size polydispersity [17]. In addition, higher temperature gives rise to shorter crystals [31].

These processes have been experimentally developed at the laboratory scale. However, their transposition towards reactor design and process engineering has not been much explored. Only two studies devoted to the optimization of acid hydrolysis of purified cellulose have been published. In a study on sulfuric acid hydrolysis of waxy maize starch granules, Angelier et al. [82] used the response surface methodology to optimize the input operating process parameters for obtaining starch nanocrystals with the smallest size within the shortest time and with the highest yield. Therefore in a first step, empirical models were elaborated for the hydrolysis yield and the size of the insoluble residues using a central composite face design involving 31 trials. The optimization showed then that it was possible to obtain starch nanocrystals after only 5 days of $\mathrm{H}_{2} \mathrm{SO}_{4}$ hydrolysis with a yield of $15 \mathrm{wt} \%$ and having the same shape as those ob- 
tained from the traditional procedure after a 40 day $\mathrm{HCl}$ treatment, with a yield of $0.5 \mathrm{wt} \%$.

Using the same methodology, Bondeson et al. [18] optimized the operating conditions of the hydrolysis and the sonication processes of a microcrystalline cellulose sample (MCC) that was derived from Norway spruce (Picea abies). In this approach, the authors analyzed the effect of the concentration of MCC and sulfuric acid, the hydrolysis time and the temperature, and the ultrasonic treatment duration on the median size and the production yield of the resulting CNs. This methodology covers various issues in data exploration, experimental design, model construction and process optimization. The constructed models were fitted to data by using a multiple linear regression with orthogonally scaled factors. The MODDE $^{\circledR} 7$ software used a Nelder Mead simplex method, with fitted response functions, to optimize an overall desirability function combining the individual desirability and weight factor of each response. The authors demonstrated that with a sulfuric acid concentration of $63.5 \%(\mathrm{w} / \mathrm{w})$, it was possible to produce CNs with a length between 200 and $400 \mathrm{~nm}$ and a thickness less than $10 \mathrm{~nm}$, in approximately $2 \mathrm{~h}$; with an unsatisfactory low yield of $30 \%$ (of initial weight) which was attributed to a possible significant amount of amorphous regions of the starting material.

However, regardless of the pretreatment of the initial material, each step of the whole process (acid hydrolysis and ultrasonic treatment), should have been modeled and optimized separately. A kinetic model would have allowed thus optimizing the operating parameters of the actual hydrolysis. Then, regarding the CNs obtained with the highest yield, a new experimental design could have been instrumental to study and model the effect of sonication power and time; then optimizing these two parameters to finally and likely get the NCCs of required quality.

In a recent work [83], acidic cation exchange resin was used as catalyst with provided advantages compared to the sulfuric acid treatment, such as reusable resin, lower equipment corrosion, lower cellulose degradation and lower environmental impact.

However, all these processes, which are based on the chemical degradation of the cellulose polymer, have significant disadvantages. As a result of the degradation to glucose or the formation of water-soluble oligomers, considered as undesirable by-products, the loss in the mass of cellulose occurs. Moreover, the use of strong mineral acids makes washing more complicated and the purification steps are necessary; therefore rendering the process and its environmental impact more complex. Industrial use of these methods on a relatively large scale may thus be disadvantageous.

\subsubsection{Enzymatic Hydrolysis}

As already mentioned in this section, enzymatic treatments enable the manufacture of CNs with significantly reduced energy consumption [27]. Most studies were performed on bleached kraft pulps. Naturally occurring cellulose fibers are not hydrolyzed by a single enzyme. In general, a set of cellulases are involved although, even in that case, cellulose must be treated with combined enzymatic treatments and high shear homogenization. This treatment decomposes and increases the accessibility of the fibers [84-89].

The main enzymes used are cellobiohydrolases, which are able to attack highly crystalline cellulose and endoglucanases which generally require some disorder in the structure to perform cellulose degradation [90,91]. Those enzymes show strong synergistic effects [26,92].

In the case of the isolation of MFC, isolated cellulases rather modify than degrade the cellulose. Pretreated fibers subjected to low enzyme concentration $(0.02 \%)$ were disintegrated efficiently while the molecular weight and the fiber length were preserved successfully [26].

Four step mechanical and enzymatic treatments $[93,94]$ were reported (i) to enhance the accessibility of the cell wall to the subsequent enzyme treatment, a refining step using an Escher-Wyss refiner was performed, (ii) followed by the treatment using the monocomponent endoglucanase enzyme, (iii) another refining stage, and last (iv) the pulp slurry was processed through a highpressure microfluidizer.

NCCs were also produced from recycled pulp using microwave aided enzymatic hydrolysis. Filson et al. (2009) [95] reported a process to produce NCC using endoglucanase enzyme. They observed that microwave heating produced NCC with better yield compared to conventional heating thanks to microwave heating being more selective and lowering the reaction time as well.

\subsubsection{CNs Surface Modification by Oxidation}

In an attempt to prevent CNs post-aggregation during the spray-drying procedures, several authors reported methods affecting the surface, such as polarity and chemical arrangements therewith, of the cellulose by oxidation processes [32,96-99].

The most widely used method is the TEMPO-mediated oxidation, in which carboxylate and aldehyde functional groups are added under moderate conditions onto the cellulose structure, employing inexpensive oxidizing agent (such as sodium hypochlorite) in the presence of the 2,2,6,6-tetramethyl-1-piperidine- $\mathrm{N}$-oxy radical (hereinafter referred to as TEMPO) and a bromide or a iodine as catalyst.

In the case of cellulose fibers hydrolyzed with hydrochloric acid, it was demonstrated [100] that the oxidation 
occurred mainly at the surface of the fibres which became negatively charged. The resulting CNs presented about the same morphology and crystallinity than those of the initial fibers and formed a homogeneous suspension when dispersed in water.

This pretreatment for producing CNs is environmentally beneficial as a reaction process to the extent that water is used as a solvent and the reaction by-product is only sodium chloride. Nevertheless, at an industrial scale the production cost of TEMPO remains a bar. Other Noxyl compounds, such as 4-hydroxy TEMPO derivative (less expensive than TEMPO) have been proposed [101103].

\subsubsection{Electrospinning}

Over the past few years, there has been a tremendous intensification of the research activities to explore electrospinning for nanofibers formation involving a large variety of materials. This quite simple and cost effective process operates on the principle that a solution is extruded-electrospun under the action of a high electric field. Once the voltage is sufficiently high, a charged stream of matter is ejected following a rather complicated loop and 3D spiral deployment trajectory. During this, the solvent evaporates leaving behind randomly oriented nanofibers accumulating on the collector. A rather common schematic diagram to depict electrospinning of polymer nanofibers is shown on Figure 4.

Pure CNs have been produced by (i) dissolving cellulose fibers in solvents, such as ethylene diamine, with a salt selected from the group consisting of potassium thiocyanate, potassium iodide and mixtures thereof, the salt being present at their saturation points (ii) using the electrospinning technique [104].

Cellulose derivative nanofibers obtained by employing electrospinning involve, their reticulation performed che- mically or by UV irradiation in concentrated crystalline liquid solutions containing isotropic solvents, such as acetone, dimethylformamide, ethanol, methanol or water $[105,106]$.

In terms of process, the effect of various parameters, including electric field strength, tip-to-collector distance, solution feed rate and composition are generally used for modeling and anticipating some of the morphological features of the electrospun nanofibers. Those can be further examined towards optimizing the input process parameters for the production of nano fibers with desirable characteristics and properties.

\subsubsection{Mechanical Processes}

Several mechanical processes have been used to extract cellulose fibrils from various raw materials. These processes include mainly refining and high-pressure homogenization, grinding, cryocrushing and high intensity ultrasonic treatments which produce high shear gradients causing transverse cleavage along the longitudinal axis of the cellulose fibers, provoking the extraction of microfibrillated cellulose (MFC).

\section{1) Refining and High-Pressure Homogenization}

This treatment consists of refining followed by a high pressure homogenizing $[107,108]$ in which a diluted cellulosic suspension is forced through a gap between a rotor and stator disk of a refiner. The disks surfaces are grooved and fitted with bars to subject the fibers to repeated cyclic frictional stresses.

During homogenization, the refined cellulose fibers are pumped at high pressure and fed through a springloaded valve assembly. As this valve opens and closes at a fast rate, the fibers are exposed to a large pressure drop with shearing and impacting forces. This combination of forces promotes a high degree of microfibrillation of the cellulose fibers, resulting in the production of MFC [109].

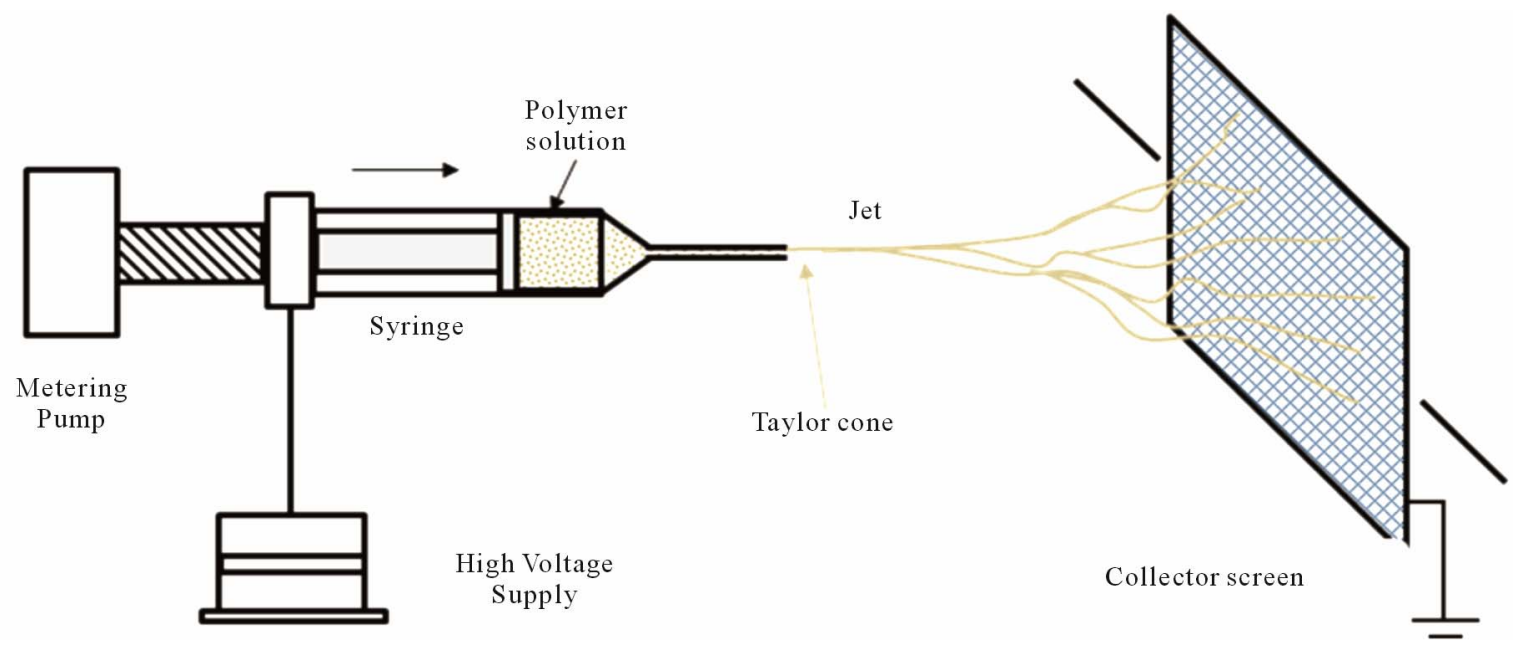

Figure 4. Principle of electrospinning process. 
Typically, the procedure is repeated several times in order to increase the degree of fibrillation. After each path, the particles become smaller and more uniform in diameter.

Various cellulosic materials such as pulps from wood, bamboo, crop straws, MCCs were treated via mechanical processes using adapted operating conditions (refining intensity and cycle frequency during the treatment....) to yield CNs' desired morphology and properties [110,111].

Moreover, diameters between 20 and $100 \mathrm{~nm}$ and lengths of several tens of micrometers were generated with the use of a microfluidizer in the homogenization step [93,112].

However, some hurdles may appear during the manufacturing of nanocellulose from pulp. These problems are associated with: (i) clogging of the homogenizer, when the pulp is pumped through high pressure/homogenizers, (ii) excessive energy consumption [109,113] unless the pulp is subjected to: acid hydrolysis prior to refining [114], oxidation by TEMPO, chemical purifications [115], enzymatic pretreatment [27], ultrasound treatment [116], addition of cellulose derivatives or polysaccharide derivatives [117], and (iii) mechanical damages of the crystalline microfibril structure or insufficient disintergration of the pulp fibers [26].

Worthwhile adding that other, more or less complex, pretreatments steps have been developed and patented for the mechanical production of CNs [118,119].

\section{2) Grinding}

Cellulose fibers can be fibrillated from a cellulose suspension passed between the static and the rotating grinding stones of a commercial grinder set at $\sim 1500 \mathrm{rpm}$. In this process, the cell wall structure is broken down by the shearing forces generating nanosized individualized fibers [120-124]. However, similarly to the refining and high-pressure homogenization processes, during grinding, mechanical damage of the fibers may occur [123].

\section{3) Cryocrushing}

Cryocrushing is an alternative method for producing nanofibers where fibers are frozen using liquid nitrogen, then high shear forces are applied [124]. Typically when the frozen fibers are under high impact forces, ice crystals exert pressure on the cell walls, causing them to rupture liberating microfibrils [125]. The cryocrushed fibers may then be dispersed uniformly into water suspension using a disintegrator before high pressure fibrillation. This process sequence is applicable to various cellulosic materials. CNs with diameter within ranges of $5-80 \mathrm{~nm}$ and length of several thousand nm were thus obtained $[39,126]$.

\section{Properties of Cellulose Nanoparticles}

The successful use of CNs in different applications re- quires an in depth understanding of their structure and properties.

\subsection{Structural and Molecular Properties}

One of the most important structural and molecular properties of CNs are geometrical dimensions (average length and width), crystallinity and average degree of polymerization which tend to vary widely, depending on the source of the cellulosic material and the conditions under which they are obtained. The heterogeneity in size can be reduced by filtration, differential centrifugation, or ultracentrifugation.

When chemical functionalities are added to CNs' surface, such as charged entities, hydrophobic groups, etc., the resulting degree of modification as well as the presence of impurities and other polymers is to be monitored (CNs rarely consist only of cellulose; the presence of other compounds may have a major impact on the CNs properties). Geometrical dimensions and crystallinity of some CNs are given in Tables $\mathbf{2}$ and $\mathbf{3 .}$

\subsection{Mechanical Properties}

Mechanical properties depend also on the source of the cellulosic material and are generally determined by several factors such as morphology, geometrical dimensions, crystal structure, crystallinity, anisotropy and defects caused by the process used for their production. Mechanical properties of different cellulose particles are given in Table 4.

\subsection{Thermal Properties}

Mostly two major thermal characteristics were determined on different CNs:

- The onset of thermal chemical degradation which occurs at $\sim 300^{\circ} \mathrm{C}$ and $\sim 260^{\circ} \mathrm{C}$ for freeze dried MCC and NCC (produced via sulfuric acid hydrolysis of the same MCC) respectively.

- The coefficient of thermal expansion in the axial direction which has been estimated at $\sim 0.1 \mathrm{ppm} / \mathrm{K}[136$ 138 ] which is similar to that of quartz glass.

\subsection{Rheological Properties}

Rheological properties were investigated on NCCs suspensions. In a "dilute" regime these suspensions are shear thinning and this behavior increases as concentration was raised. Concentration dependence was clearly observed at low shear rates but not at high shear rates. However, at high concentrations where the suspension is lyotropic, anomalous transitions occurred in the flow showing that at a critical shear rate, the nanocrystals align themselves due to their rod-like nature, then greatly smoothing their 
A Review of Available Data and Industrial Applications

Table 2. Geometrical dimensions: length (L) and diameter (d) of NCs from various sources obtained via various techniques.

\begin{tabular}{|c|c|c|c|c|}
\hline Source & Length (nm) & Width (nm) & Technique & Ref. \\
\hline Soft wood pulp & $100-150$ & $4-5$ & AFM & [17] \\
\hline Hard wood pulp & $140-150$ & $4-5$ & AFM & [17] \\
\hline Ramie & $150-250$ & $6-8$ & TEM & [66] \\
\hline Sisal & $100-500$ & $3-5$ & TEM & [35] \\
\hline Tunicate & 1160 & 16 & DDL & [127] \\
\hline Valonia & $>1000$ & $10-20$ & TEM & [45] \\
\hline Bacterial & $100-1000$ & $10-50$ & TEM & [79] \\
\hline MCC & $\sim 500$ & 10 & AFM & [7] \\
\hline
\end{tabular}

Table 3. Crystallinity of various NCs.

\begin{tabular}{|c|c|c|c|}
\hline Particle type & Crystallinity (a) (\%) & I $\beta$ (b) (\%) & Ref. \\
\hline Wood and Plant pulps & $43-65$ & - & {$[2]$} \\
\hline MCC & $80-85$ & - & [18] \\
\hline MFC & $51-69$ & $10-66$ & [128] \\
\hline NCC & $54-88$ & $68-94$ & {$[31,128]$} \\
\hline Tunicate NCC & $85-100$ & $76-90$ & {$[31,128]$} \\
\hline Valonia & - & $36-42$ & {$[45-47]$} \\
\hline Bacterial (Acetobacter) & 63 & $3-27$ & {$[52]$} \\
\hline
\end{tabular}

(a): Degree of crystallinity relative to cellulose; (b): fraction of $\mathrm{I} \beta$ crystal structure.

Table 4. Mechanical properties of various NCs.

\begin{tabular}{|c|c|c|c|c|c|c|c|}
\hline \multicolumn{2}{|c|}{ Source } & $\mathbf{E}_{\mathrm{A}}$ & $\mathbf{E}_{\mathrm{T}}$ & $\sigma_{\mathrm{f}}$ & $\varepsilon_{\mathbf{f}}(\mathbf{\%})$ & Technique & Ref. \\
\hline \multicolumn{2}{|c|}{ WP } & $14-27$ & - & $0.3-1.4$ & $4-23$ & Tensile & [129] \\
\hline \multicolumn{2}{|c|}{ PP } & $5-45$ & - & $0.3-0.8$ & $1.3-8$ & Tensile, Raman & [130-131] \\
\hline \multicolumn{2}{|c|}{ MCC } & 25 & - & - & - & Raman & [131] \\
\hline \multirow{2}{*}{ NCC } & WP & $50-100$ & $18-50$ & - & - & AFM indentation & [132] \\
\hline & $\mathrm{PP}$ & 57,105 & - & - & - & Raman & [133] \\
\hline \multicolumn{2}{|c|}{ Tunicate NCC } & 143 & - & - & - & Raman & [134] \\
\hline \multicolumn{2}{|c|}{ Bacterial NCC } & 134 & - & - & 2 & Raman & [135] \\
\hline
\end{tabular}

$\mathrm{E}_{\mathrm{A}}=$ elastic modulus in axial direction $(\mathrm{GPa}) ; \mathrm{E}_{\mathrm{T}}=$ elastic modulus in transverse direction $(\mathrm{GPa}) . \sigma_{\mathrm{f}}=$ tensile strength (tensile testing) $(\mathrm{GPa}) ; \varepsilon_{\mathrm{f}}=$ strain to failure (tensile testing) (\%); WP = Wood pulp; PP = Plant pulp.

flow. The rates at which such transitions in the flow behavior occur are concentration dependant. Rheometry measurements performed on NFCs suspensions prepared via TEMPO-oxidation [139] also showed shear-thinning behavior following a power-law and thixotropy. Those are explained through percolation in the fibrils and flock formation. Some more investigations into the properties of CNs showed that wood and bacterial CNs exhibit an amazing water-storage capacity. A dispersion of those nanocelluloses in water with a solid content of only $2 \%$ leads to a mechanically stable transparent gel. It should also be noted that wood NCCs prepared by mechanical treatment seems to have much lower moduli (50 - 100 GPa) [133] than those of bacterial NCCs. 


\section{Processes for the Surface Transformation of CNs}

Three distinct surface modifications of CNs are generally used (i) via processing during CNs extraction, (ii) adsorption of molecules to the surface of the particles, and chemical modifications including covalent bonding of molecules onto the surface.

\subsection{Transformation during CNs Extraction}

Sulfuric acid hydrolysis promotes the formation of sulfate esters therewith high surface acidity. Hydrochloric acid hydrolysis results in hydroxylated surfaces [17].

As already mentioned, sulfuric acid treatment is the most commonly used method as the resulting high sulfate tend to stabilize nanocrystals dispersion.

TEMPO-mediated oxidation already described in Section 3, is also used during CNs extraction. This pretreatment of the CNs surface yields a carboxylic acid rich surface.

\subsection{Transformation by Adsorption}

The overall objective is to reduce CNs surface energy in order to improve their dispersibility/compatibility with non-polar media. Noncovalent surface modifications of CNs are typically made via adsorption of surfactants such as stearic acid [140], cetyltetramethylammonium bromide [141], xyloglucan, xyloglucan block copolymers, mono- and di-esters of phosphoric acid with alkylphenol tails [142,143].

Most commonly, layer-by-layer deposition is used [144]; thus, obtained surfactant-coated CNs dispersed very well in nonpolar solvents [142].

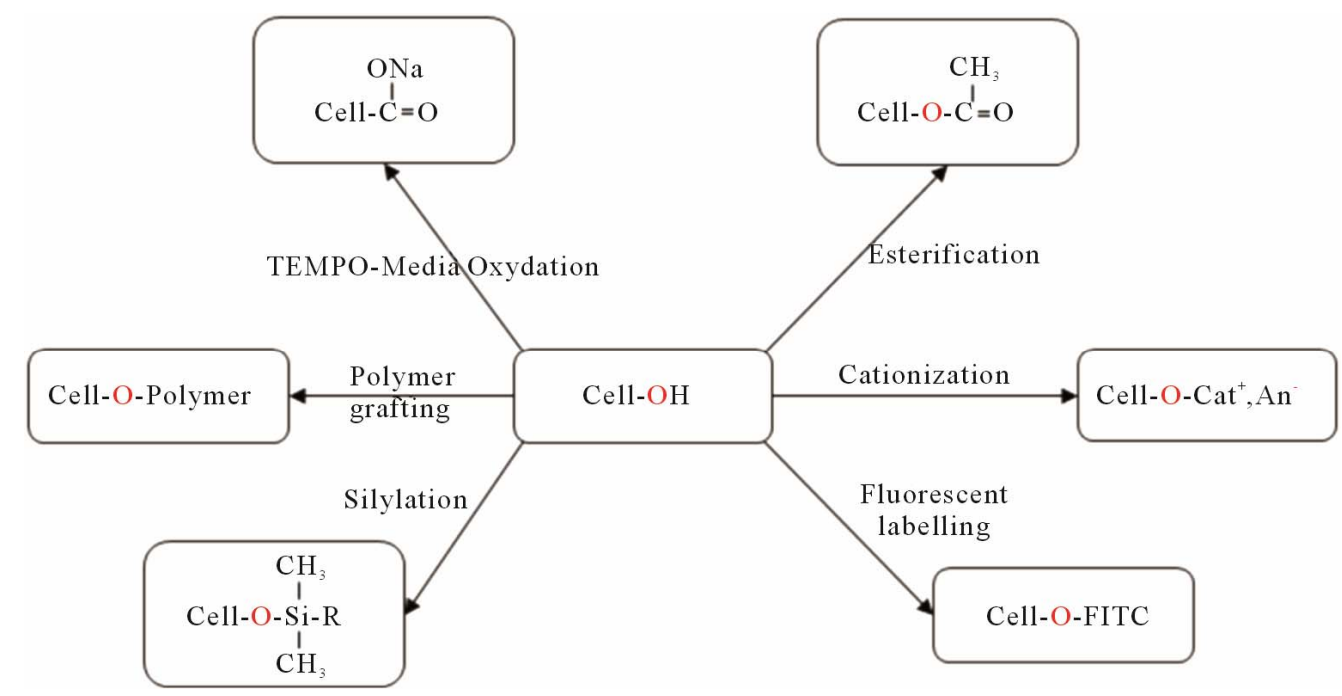

\subsection{Chemical Transformations of NCCs}

Nanocelluloses possess an abundance of hydroxyl groups on their surface, providing the possibility of extensive chemical modifications. Most of these modifications are aiming at improving (i) the dispersibility of NCCs by reducing the hydrogen bonds which cause the re-aggregation of the crystals during the spray-drying step of the production process and (ii) the compatibility of NCCs in different solvents or matrices that are suitable in the production of nanocomposites. The main chemical modifications of NCC are esterification, silylation, cationisation, fluorescent labeling, carboxylation by TEMPO-Media oxidation, and polymer grafting [145-149] (Figure 5). Although those operations decrease the surface energy and polar character of the nanoparticles-although improving the adhesion with non polar polymeric matrix - a detrimental effect is generally reported concerning the mechanical performances of the composite. This unusual behavior is ascribed to the originality of the reinforcing phenomenon associated with nanocelluloses, which results from the formation of a so-called percolated network thanks in part to hydrogen bond force. Moreover, experimental conditions used for these surface chemical modifications should avoid media swelling and the peeling effect of surface-grafted chain generally inducing their dissolution in the reaction medium. The chemical grafting has to be mild enough in order to preserve the integrity of the nanoparticles.

\subsubsection{Esterification}

Several methods had been employed to achieve the surface acetylation [148,150-152], and the esterification processes $[153,154]$ of NCCs. Avoiding swelling conditions,

fluorescein-5-isothiocyanate). 
the reaction only occurred on the cellulose chains located at the NCCs surface.

The limitation of the extent of esterification lies in the receptiveness and accessibility of hydrolyzed NCCs on the surface.

The nature and extraction treatment of NCCs appeared to be an important factor controlling the extent of esterification and the final morphology of NCCs. Grafting fatty acids of different aliphatic chain length (up to 18) was achievable; while the crystalline core was barely unaffected.

\subsubsection{Silylation}

Cellulose whiskers from acid hydrolysis of tunicate were silylated partially with a series of alkyldimethyl-chlorosilanes, with alkyl moieties such as isopropyl, n-butyl, noctyl and n-dodecyl [145] (Figure 6).

Partially silylated whiskers with degree of substitution (DS) between 0.6 and 1 can readily be redispersed in medium polarity organic solvents, such as acetone and THF. At DS of less than 0.6, the morphological integrity of the whiskers was preserved, however disrupted when the DS was greater than 1 . The authors [145] developed a model with four silylating agents to describe the experimental observations made at different DS. Moreover, the partially silylated whiskers were found to be more swollen compared to the needle-like images of unmodified whiskers, indicating the occurrence of slight silylation of the NCC core.

In addition, the surface trimethyl silylation of NCC from bacterial cellulose and their reinforcement characteristics in nanocomposites were also investigated [78].

\subsubsection{Cationization}

A one step method has been developed to introduce positive charges onto the surface of NCC through the grafting of epoxypropyltrimethylammonium chloride [147]. This process, carried out under mild operating conditions, reverses the surface charge and leads to stable aqueous suspensions of NCC with unexpected thixotropic gelling properties while preserving the original morphology and maintaining the integrity of the crystal.

\subsubsection{Fluorescently Labeled NCC}

Fluorescence techniques were used significantly to study the cellular uptake and biodistribution of nanoparticulate

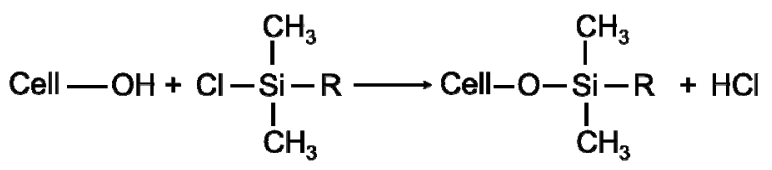

Figure 6. Preparation of silylated cellulose whiskers $(\mathbf{R}=$ i- $\mathrm{C}_{3} \mathrm{H}_{7}, \mathbf{n}-\mathrm{C}_{4} \mathrm{H}_{9}, \mathbf{n}-\mathrm{C}_{8} \mathrm{H}_{17}, \mathbf{n}-\mathrm{C}_{12} \mathrm{H}_{25}$ ). delivery systems, by tracking the fluorophores.

An interesting method [155] to label NCC with fluorescein-5-isothiocyanate for fluorescence bioassay and bioimaging applications was described. The process was carried out in three steps.

First, epoxy functional groups were fixed at the surface of NCC via reaction with epichlorohydrin. Then the epoxy ring was opened with ammonium hydroxide to introduce primary amino groups. Finally, the primary amino group was reacted with isothiocyanate group of FITC to form a thiourea.

\subsubsection{Polymer Grafting}

The methods for polymer grafting onto NCC surface are based on two approaches, named "grafting-onto" and “grafting-from” [66,149,156-158].

"Grafting-onto" consists in directly grafting an existing polymer on NCCs surface with the use of a coupling agent. The main advantage of this technique is that the polymer can be fully characterized before grafting and then it is possible to control the properties of the resulting material. The main drawback is due to steric hindrance and high viscosity of the medium.

"Grafting-from" consists in mixing NCCs with a monomer and an initiator. The polymer grows directly on the surface of the nanoparticles. The main advantage of this approach is that the reaction is fast and easy because there is no steric hindrance and the viscosity of the reaction medium remains low. The main drawback is that the grafted polymer is not initially fully characterized.

In these approaches, nanocelluloses are never dried before grafting but solvent is exchanged from water to organic solvent. For that, aqueous suspension with desired amount of NCCs (1 wt \%) are solvent exchanged to acetone and then to dry organic solvent by several successive centrifugation and redispersion operations. Sonication must be performed after each solvent exchange step to avoid aggregation. Both modifications exhibit a large effect on the individualization of the nanocrystals due to reduced hydrogen bonding and polar interactions between the individual particles.

The "grafting-onto" approach was used to graft onto NCCs various polymers such as polycaprolactone, via isocyanate-mediated coupling reaction [34], presynthesized waterborne polyurethane [74], thermo-responsive polymers, via a peptidic coupling reaction [159], maleated polypropylene [160], DNA oligomers onto the surface of TEMPO oxidized NCC [161].

The "grafting-from" approach was used to grow polymeric chains from the NCC surface via the atom transfer radical polymerization (ATRP). This technique allows for very precise control over the grafting process that produces well-defined monodisperse particles [162]. It is 
a two-step process in which the first step consists in esterification of hydroxyl groups on NCC surface with 2bromoisobuturyl bromide, while the second step consists in the polymerization of monomers. Various monomers were used such as styrene [149], styrene with N,N-dimethylaminoethyl as hydrophilic monomer [156]. N,N-dimethylaminoethyl methacrylate (DMAEM) [163] was also used to study the temperature induced chiral nematic phase behaviour of suspensions of PDMAEM-grafted NCC.

Ring-opening polymerization was also used in the "grafting-from" approach to graft polycaprolactone polymers onto NCC surface [66], where $\left(\mathrm{Sn}(\mathrm{Oct})_{2}\right)$ was used as a grafting and polymerizing agent.

To enhance the grafting efficiency, similar grafting processes via microwave irradiation were studied [164, $165]$.

\section{Processes for the Production of Nanocellulosic-Based Materials}

Thanks to their interesting physical, mechanical and chemical properties, abundance, low weight and biodegradability, CNs have the potential of becoming an important class of renewable nanomaterials for many applications. The properties of each obtained materials have been discussed in the numerous papers already published and they will not be presented in this review.

\subsection{Production of Nanocomposites}

The manufacture of CN-based nanocomposites by dispersing cellulose nanoparticles in a matrix implies to take into consideration $\mathrm{CN}$ intrinsic properties, interfacial characteristics, structure and properties of the matrix and, finally, the desired end-use properties of the resulting composites.

Moreover, the processing temperature shall be restricted to $\sim 180^{\circ} \mathrm{C}$ because $\mathrm{CN}$ starts to degrade nearby this temperature range. This limits the type of thermoplastics which can be used.

The CN characteristics that motivate its applications as nanofiller include:

- a high aspect ratio (length/width), which enables good stress transfer between filler and matrix;

- the high contact surface due to nanometric dimensions, which results in improved properties using rather low filler concentration;

- the presence of hydroxyl groups on the surface, that facilitates reactions;

- the use of renewable sources for their production, which is a major feature of their use in the development of environmentally-friendly materials.

In this direction, most scientific works have focused on $\mathrm{CN}$ reinforced polymer composites and the research in this domain has been extensively reviewed $[4,21,22$, 166-168]. For detailed descriptions, the reader is referred to these earlier reviews. The following section will provide a brief summary of composite processing and the role of particle alignment on properties.

Favier et al. (1995) [11] was apparently the first to report their use as reinforcing fillers in poly(styrene-cobutyl acrylate)-based nanocomposites. Since then, numerous nanocomposite materials have been developed by incorporating NCC into a wide range of polymeric matrices [4]. The properties of the resulting nanocomposites depend on the types and the characteristics of NCC on one side and the polymeric matrices on the other side (which could be both natural and synthetic polymers) [167].

However, as for any nanoparticles, the main challenge is related to their homogeneous dispersion within a polymeric matrix. Water could be considered as the preferred processing medium because of the high stability of aqueous CN dispersions. To ensure a good level of dispersion, this implies to use either hydrosoluble polymers or aqueous dispersed polymers, i.e., latexes as a matrix. In this context a majority of patents [169-176] described CNbased nanocomposites produced in aqueous media.

Many other non-polar reinforced polymer nanocomposites were developed with $\mathrm{CN}$ dispersed in adequate organic medium using surfactants [142,177] or organic solvents [178-181].

Four main processing techniques have been utilized to produce CN composites: casting-evaporation [4,21,166], electrospinning [182-185], melt compounding [4,166,168] and impregnation [166].

\subsubsection{Casting-Evaporation Process}

Casting-evaporation is one of the most common techniques used to produce nanocomposite films. In general, NCC is dispersed within a given medium (0.05 - $5 \mathrm{wt} \%$ solids), typically water, but various organic mediums have also been used and then polymer solutions are mixed with the NCC dispersion.

Composite films can then be produced from this mixture via three useful techniques:

- casting on a suitable surface followed by evaporation,

- freeze-drying and compression molding,

- freeze-drying, extruding, and then compression molding of the mixture.

To achieve good reinforcement, the dispersibility of NCC in both the polymeric matrix and processing solvents is critical. The water-soluble matrix is the simplest system for incorporating NCC as filler, due to the hydrophilic character of NCC.

The properties of nanocomposite films based on eth- 
ylene oxide/epichlorohydrin and NCC, produced by dispersion-casting of NCC fillers in THF/water mixtures were reported [186].

The polymer grafting is beneficial for dispersing NCC and to formulate nanocomposites in non-polar solvents [160]. However, drying and redispersion of NCC without aggregation in casting-evaporation processing is still a challenge to overcome more easily. Nanocomposite films using unmodified and PCL-grafted NCC nanoparticles as filler and PCL as the matrix were prepared [34]. The authors found that PCL-grafted nanoparticles were easily dispersed when compared to the unmodified system. They demonstrated that the transformation of NCC nanoparticles into a cocontinuous material through long chain surface chemical modification represents a new and promising way for the processing of nanocomposite material.

Various modifications of this method (e.g. CN surface functionalization, etc.) have been developed to improve CN dispersion and are summarized elsewhere [4,21].

\subsubsection{Electrospinning Process}

This technique, already described in section 2.2.4 is a fast and simple process to produce polymeric filaments. It has been widely studied [182-185]. In general, NCC is dispersed within a given medium (typically 0.05 - $5 \mathrm{wt} \%$ solids) and then polymer solutions are mixed with the $\mathrm{CN}$ dispersion. Using this technique, the solvent evaporates as the fiber moves between the source and the collector and the polymer coagulates, forming a composite fibre. The NCC reinforced fibers can be further dried and/or go through additional treatments (e.g. heating to crosslink the matrix polymer).

Research efforts have focused on improved alignment of CNs along the fiber length, on tailored CN-matrix interfacial properties, and on the improved mechanical properties $[184,185]$.

\subsubsection{Melt-Compounding Processes}

In general, these processes involve the incorporation of $\mathrm{CN}$ into thermoplastic polymers by using thermal-mechanical mixing, extrusion of the melt mixture, and optional compression molding into specific test specimen geometries and configurations.

The extrusion process operating parameters must be carefully controlled to minimize $\mathrm{CN}$ and matrix degradation resulting from shear stresses or temperature (CN degradation occurring at $\mathrm{T}>180^{\circ} \mathrm{C}$ as mentioned before). Therefore only few studies $[187,188]$ have been reported concerning the processing of nanocellulose-reinforced nanocomposites by extrusion methods. Moreover, the extrusion of CN grafted with long chain molecules seems to be much easier and can be processed in solvent free conditions, especially when the grafted chains can melt at the processing temperature [154,164].

\subsubsection{Impregnation Processes}

This technique is mostly used for sample preparation for evaluating the mechanical $[9,189]$, thermal [190] and optical [191] properties of cellulose-filled composites.

A cellulose thin film is first prepared via membrane filtration of a NCC solution or by pressing dried NCC. At low pressure, this film is then impregnated by immersing it in a thermosetting resin and cured to produce a dried film or mat composite. This technique was developed on various NCCs [190,192,193].

\subsection{Monolayer Films}

Monolayer neat CN films consist of $100 \mathrm{wt} \%$ cellulose particles interconnected by extensive further reaching hydrogen bonding in a network structure. In general, CNs are dispersed in water or organic solvent $(0.05-5 \mathrm{wt} \%$ solids). Films can be produced by casting-evaporation at moderate temperature [122,194], freeze-drying [195], or solvent exchange [194-196] processes.

\subsection{Multilayer Films}

In this method, two different components are alternately deposited by solution-dipping or spin-coating. Strong interactions are usually developed between the alternative layers. This rather facile method of layer-by-layer assembly has been useful to produce multilayered films based on CNs for fabricating composite films with nanometer precision [144,197-200].

\section{Nanocellulose Applications}

Due to their physical and mechanical properties, CNs can be designed for a great variety of applications, ranging from technological to medical domains [5,201,202].

\subsection{Nanocellulose for Biomedical Applications}

Nanocellulose is a biomaterial highly applicable to biomedical industry. Formulations with nanocellulose and silver nanoparticles can particularly be used as microbial medicaments, antibacterial agents in wound dressing, bandages, implants, skins replacements for burnings, face masks, artificial blood vessels, cuffs for nerve surgery, drug delivery, cell carriers and support matrices for enzyme immobilization, cosmetic tissues etc. [203-216].

\subsection{Nanocellulose for Technical Applications}

As a unique material, cellulose in its different CNs forms is currently used in several technical applications. As already mentioned, nanocellulose combines desirable phy- 
sical and morphological properties that enable its use in a great variety of applications [22].

Specifically, cellulose nanofibers can be used as filtration membranes [217-219].

Chemical modifications of cellulose surface are also a promising strategy to improve mechanical and thermal properties of different polymers, for technical applications [22,220]

As a consequence, surface modified cellulose nanofibers can be used for many applications such as coating, adhesives, sealings, filters, membranes, packing and cosmetics, aerospace industry, optically transparent flexible devices such as flat displays, digital cameras, cellular telephones and integrated circuits, paper or board for printing and recording information liquid crystals for transparent windows, lamps or dials of clocks and watches etc. [221-226].

\section{Conclusions}

This paper reviews the most recent processes developed to produce and transform cellulose nanoparticles and to manufacture nanocellulose-based materials with many applications in the emerging area of nanotechnology. Indeed, to this day, most of the studies clearly show that the processes developed for the production of NCs include (i) a step for obtaining pure cellulose and (ii) a nanofibrillation step which can be achieved through chemical, enzymatic or mechanical techniques. The resulting products have nano-sized dimensions, a crystalline structure and physical properties which, combined with their "friendliness" and their biodegradability, make them materials of choice in the very promising area of bionanotechnology, opening up major commercial markets in line with the green chemistry trend. Within this framework, the various laboratories involved in this domain have developed many bio-products that become industrial reality through their numerous potential applications; not to underestimate some important steps which remain to be overcome and need to be addressed both fundamentally and practically. At this level, the pilot units, as well as the demonstration plants such as those mentioned in section one, are now used to improve, optimize and scale-up the processes developed at a laboratory scale and to engineer new products with new functionalities. This will inevitably favor the designing of industrial size performing reactors in suitable environments and modern control equipment.

Finally additional synergism can be expected and promoted.

Work done in the field of high performance fibers and nanostructures can be translated to nanocellulose materials in terms of fundamental and practical understanding and know-how; for example studies conducted by the authors should find valuable applications in the field of this review and may constitute a beneficial follow-up of this work.

Indeed Rebouillat et al. [227-246] have made and reported considerable amount of work to characterize fiber surface treatments as well as joint adhesion structural strength and ageing performance. For example, combined with other analytical tools the DMA (Dynamic Mechanical Analysis) and DMTA (Dynamic Mechanical Thermal Analysis) are able to compete with DSC (Differential Scanning Calorimetry), combined or not with TGA (Thermo Gravimetric Analysis) to identify polymeric transitions and to a certain extend sub-transitions. Those are directly applicable to the matter of interest of this review. As underlined in the same cited references, especially suitable applications are associated with the use of aramids and carbon fibers, especially aramid fibers, which most of the time are also used as reinforcing elements, therefore impregnated, such as in aeronautic, aerospace, marine, automotive, military and civil protection enduses.

An area of significant interest might be to further combine such high performance materials with cellulosic nanostructures and to determine the value of such new high performance hybrids.

The processing dimension will remain evolutionary and likely "revolutionary"; hopefully this review will serve as a solid "starting" point.

\section{REFERENCES}

[1] D. Klemm, H. Schmauder and T. Heinze, "Cellulose," Biopolymers, Vol. 6, 2002, pp. 275-319.

[2] D. Klem, B. Heublein, H. Fink and A. Bohn, "Cellulose: Fascinating Biopolymer and Sustainable Raw Material,” Angewandte Chemie International Edition, Vol. 44, No. 22, 2005, pp. 3358-3393. doi:10.1002/anie.200460587

[3] L. Petersson, I. Kvien, K. Oksman, "Structure and Thermal Properties of Poly(Lactic Acid)/Cellulose Whiskers Nanocomposite Materials," Composites Science and Technology., Vol. 67, No. 11-12, 2007, pp. 2535-2544. doi:10.1016/j.compscitech.2006.12.012

[4] Y. Habibi, L. A. Lucia and O. J. Rojas, "Cellulose Nanocrystals: Chemistry, Self-Assembly, and Applications," Chemical Review, Vol. 110, No. 6, 2010, pp. 3479-3500. doi:10.1021/cr900339w

[5] D. Klemm, F. Kramer, S. Moritz, et al., "Nanocelluloses: A New Family of Natural-Based Materials," Angewandte Chemie International Edition, Vol. 50, No. 24, 2011, 5438-5466. doi:10.1002/anie.201001273

[6] S. J. Eichhorn, C. A. Baillie, N. Zafeiropoulos, L. Y. Mwaikambo, M. P. Ansell, A. Dufresne, K. M. Entwistle, P. J. Herrera-Franco, G. C. Escamilla, L. Groom, M. Hugues, C. Hill, T. G. Rials and P. M. Wild, "Review: Current International Research into Cellulosic Fibres and 
Composites," Journal of Materials Science, Vol. 36, No. 9, 2001, pp. 2107-2131. doi:10.1023/A:1017512029696

[7] L. Pranger and R. Tannenbaum, "Biobased Nanocomposites Prepared by in Situ Polymerization of Furfuryl Alcohol with Cellulose Whiskers or Montmorillonite Clay,” Macromolecules, Vol. 41, No. 22, 2008, pp. 8682-8687. doi:10.1021/ma8020213

[8] D. Klemm, D. Schumann, F. Kramer, N. Hessler, M. Hornung, H. P. Schmauder and S. Marsch, "Nanocelluloses as Innovative Polymers in Research and Application," Polysaccharides, Vol. 205, 2006, pp. 49-96.

[9] M. Henriksson and L. A. Berglund, "Structure and Proerties of Cellulose Nanocomposite Films Containing Melamine Formaldehyde," Journal of Applied Polymer Science, Vol. 106, No. 4, 2007, pp. 2817-2824. doi:10.1002/app.26946

[10] S. Iwamoto, A. N. Nakagaito and H. Yano, "Nanofibrillation of Pulp Fibers for the Processing of Transparent Nanocomposites," Applied Physics A: Materials Science \& Processing, Vol. 89, No. 2, 2007, pp. 461-466. doi:10.1007/s00339-007-4175-6

[11] V. Favier, H. Chanzy and J. Y. Cavaille, "Polymer Nanocomposites Reinforced by Cellulose Whiskers," Macromolecules, Vol. 28, No. 18, 1995, pp. 6365-6367. doi:10.1021/ma00122a053

[12] F. A. L. Clowes and B. E. Juniper, "Plant Cells," Blackwell Science Ltd., Oxford, 1968.

[13] H. A. Krässig, "Cellulose Structure, Accessibility and Reactivity," Gordon and Breach Science Publishers, Yverdon, 1993, pp. 307-314.

[14] H. C. Brittain, G. Lewen, A. W. Newman, K. Fiorelli and S. Bogdanowich, "Changes in Material Properties Accompanying the National Formulary (NF) Identity Test for Microcrystalline Cellulose,” Pharmaceutical Research, Vol. 10, No. 1, 1993, pp. 61-67. doi:10.1023/A:1018921012812

[15] N. Y. Uesu, E. A. G. Pineda and A. A. W. Hechenleitner, "Microcrystalline Cellulose from Soybean Husk: Effects of Solvent Treatments on Its Properties as Acetylsalicylic Acid Carrier," International Journal of Pharmaceutics, Vol. 206, No. 1-2, 2000, pp. 85-96 doi:10.1016/S0378-5173(00)00532-9

[16] B. L. Peng, N. Dhar, H. L. Liu and K. C. Tam, "Chemistry and Applications of Nanocrystalline Cellulose and Its Derivatives: A Nanotechnology Perspective,” The Canadian Journal of Chemical Engineering, Vol. 89, No. 5, 2011, pp. 1191-1206. doi:10.1002/cjce.20554

[17] S. Beck-Candanedo, M. Roman and D. G. Gray, "Effect of Reaction Conditions on the Properties and Behavior of Wood Cellulose Nanocrystals Suspensions,” Biomacromolecules, Vol. 6, No. 2, 2005, pp. 1048-1054. doi:10.1021/bm049300p

[18] D. Bondeson, A. Mathew and K. Oksman, “Optimization of the Isolation of Nanocrystals from Microcrystalline Cellulose by Acid Hydrolysis," Cellulose, Vol. 13, No. 2, 2006, pp. 171-180. doi:10.1007/s10570-006-9061-4

[19] X. Li, E. Ding and G. Li, "A Method of Preparing
Spherical Nanocrystals Cellulose with Mixed Crystalline Forms of Cellulose I and II," Chinese Journal of Polymer Science, Vol. 19, No. 3, 2001, pp. 291-296.

[20] M. T. Postek, A. Vladar, J. Dagata, et al., "Cellulose Nanocrystals the Next Big Nano-Thing?” Proceedings of SPIE-The International Society for Optical Engineering, San Diego, 10 August 2008, p. 7042

[21] M. A. Hubbe, O. J. Rojas, L. A. Lucia and M. Sain, "Cellulosic Nanocomposites-A Review," BioResources, Vol. 3, No. 3, 2008, pp. 929-980.

[22] I. Siro and D. Plackett, "Microfibrillated Cellulose and New Nanocomposite Materials: A Review,” Cellulose, Vol. 17, No. 3, 2010, pp. 459-494. doi:10.1007/s10570-010-9405-y

[23] P. Stenius and M. Andresen, "Highlights in Colloid Science,” Wiley-VCH Verlag GmbH \& Co. KGaA, Weinhelm, 2009, pp. 135-154.

[24] W. Stelte and A. R. Sanadi, "Preparation and Characterization of Cellulose Nanofibers from Two Commercial Hardwood and Softwood Pulps,” Industrial and Engineer Chemistry Research, Vol. 48, No. 24, 2009, pp. 1121111219. doi:10.1021/ie9011672

[25] R. H. Marchessault, F. F. Morehead and N. M. Walter, "Liquid Crystal Systems from Fibrillar Polysaccharides," Nature, Vol. 184, No. 4686, 1959, pp. 632-633. doi:10.1038/184632a0

[26] M. Henriksson, G. Henriksson, L. A. Berglund and T. Lindström, “An Environmentally Friendly Method for Enzyme Assisted Preparation of Microfibrillated Cellulose (MFC) Nanofibers," European Polymer, Vol. 43, No. 8, 2007, pp. 3434-3441. doi:10.1016/j.eurpolymj.2007.05.038

[27] M. Pääkkö, M .Ankerfors, H. Kosonen, A. Nykanen, S. Ahola, M. Osterberg, J. Ruokolainen, J. Laine, P. T. Larsson, O. Ikkala and T. Lindström, "Enzymatic Hydrolysis Combined with Mechanical Shearing and HighPressure Homogenization for Nanoscale Cellulose Fibrils and Strong Gels,” Biomacromolecules, Vol. 8, No. 6, 2007, pp. 1934-1941. doi:10.1021/bm061215p

[28] E. Abraham, B. M. Cherian, C. N. George and L. A. Pothan, "Process for Synthesis of Nanofibrils of Natural Fibers by Steam Explosion,” IN200702267-I4, 2010.

[29] H. H. Anette, "Preparation of Microfibrillar Polysaccharide Used to Provide Microfibrillar Cellulose Comprises Treating Polysaccharide in Aqueous Suspension Having Oxidant and Transition Metal, and Mechanically Delaminating of Polysaccharide,” WO2007001229-A1, 2007.

[30] F. A. Agblevor, M. M. Ibrahim and W. K. El-Zawawy, "Coupled Acid and Enzyme Mediated Production of Microcrystalline Cellulose from Corn Cob and Cotton Gin Waste," Cellulose, Vol. 14, No. 3, 2007, pp. 247-256. doi:10.1007/s10570-006-9103-y

[31] S. Elazzouzi-Hafraoui, Y. Nishiyama, J. L. Putaux, L. Heux, F. Dubreuil and C. Rochas, "The Shape and Size Distribution of Crystalline Nanoparticles Prepared by Acid Hydrolysis of Native Cellulose," Biomacromolecules, Vol. 9, No. 1, 2008, pp. 57-65. doi:10.1021/bm700769p 
[32] T. Saito, Y. Nishiyama, J. L. Putaux, M. Vignon and A. Isogai, "Homogeneous Suspensions of Individualized Microfibrils from TEMPO-Catalyzed Oxidation of Native Cellulose,” Biomacromolecules, Vol. 7, No. 6, 2006, pp. 1687-1691. doi:10.1021/bm060154s

[33] B. S. L. Brito, F. V. Pereira, J. L Putaux and B. Jean, "Preparation, Morphology and Structure of Cellulose Nanocrystals from Bamboo Fibers,” Cellulose, Vol. 19, No. 5, 2012, pp. 1527-1536. doi:10.1007/s10570-012-9738-9

[34] Y. Habibi and A. Dufresne, "Highly Filled Bionanocomposites from Functionalised Polysaccharide Nanocrystals," Biomacromolecules, Vol. 9, No. 7, 2008, pp. 19741980. doi: $10.1021 / \mathrm{bm} 8001717$

[35] N. L. G. de Rodriguez, W. Thielemans and A. Dufresne, "Sisal Cellulose Whiskers Reinforced Polyvinyl Acetate Nanocomposites,” Cellulose, Vol. 13, No. 3, 2006, pp. 261-270. doi:10.1007/s10570-005-9039-7

[36] G. Siqueira, J. Bras and A. Dufresne, "Cellulose Whiskers versus Microfibrils: Influence of the Nature of the Nanoparticle and Its Surface Functionalization on the Thermal and Mechanical Properties of Nanocomposites," Biomacromolecules, Vol. 10, No. 2, 2009, pp. 425-432. doi:10.1021/bm801193d

[37] W. Helbert, J. Y. Cavaille and A. Dufresne, “Thermoplastic Nanocomposites Filled with Wheat Straw Cellulose Whiskers. Part I: Processing and Mechanical Behavior,” Polymer Composites, Vol. 17, No. 4, 1996, pp. 604611. doi:10.1002/pc.10650

[38] A. Dufresne, J. Y. Cavaille and W. Helbert, "Thermoplastic Nanocomposites Filled with Wheat Straw Cellulose Whiskers. Part II: Effect of Processing and Modeling," Polymer Composites, Vol. 18, No. 2, 1997, pp. 198-210. doi:10.1002/pc.10274

[39] A. Alemdar and M. Sain, "Isolation and Characterization of Nanofibers from Agricultural Residues-Wheat Straw and Soy Hulls,” Bioresource Technology, Vol. 99, No. 6, 2008, pp. 1664-1671. doi:10.1016/j.biortech.2007.04.029

[40] T. Zimmermann, N. Bordeanu and E. Strub, "Properties of Nanofibrillated Cellulose from Different Raw Materials and Its Reinforcement Potential," Carbohydrate Polymers, Vol. 79, No. 4, 2010, pp. 1086-1093. doi:10.1016/j.carbpol.2009.10.045

[41] S. Kimura and T. Itoh, "New Cellulose Synthesizing Complexes (Terminal Complexes) Involved in Animal Cellulose Biosynthesis in Tunicate Metandrocarpa uedai," Protoplasma, Vol. 194, No. 3-4, 1996, pp. 151-163. doi:10.1007/BF01882023

[42] W. Helbert, Y. Nishiyama, T. Okano and J. Sugiyama, "Molecular Imaging of Halocynthia papillosa Cellulose," Journal of Structural Biology, Vol. 124, No. 1, 1998, pp. 42-50. doi:10.1006/jsbi.1998.4045

[43] S. Kimura and T. Itoh, "Cellulose Synthesizing Terminal Complexes in the Ascidians," Cellulose, Vol. 11, No. 3-4, 2004, pp. 377-383. doi:10.1023/B:CELL.0000046414.72903.33

[44] S. Iwamoto, W. H. Kai, A. Isogai and T. Iwata, "Elastic Modulus of Single Cellulose Microfibrils from Tunicate
Measured by Atomic Force Microscopy," Biomacromolecules, Vol. 10, No. 9, 2009, pp. 2571-2576. doi:10.1021/bm900520n

[45] J. F. Revol, "On the Cross-Sectional Shape of Cellulose Crystallites in Valonia ventricosa," Carbohydrate Polymers, Vol. 2, No. 2, 1982, pp. 123-134. doi:10.1016/0144-8617(82)90058-3

[46] J. Sugiyama, H. Harada, Y. Fujiyoshi and N. Uyeda, "Lattice Images from Ultrathin Sections of Cellulose Microfibrils in the Cell Wall of Valonia macrophysa Kütz," Planta, Vol. 166, No. 2, 1985, pp. 161-168. doi:10.1007/BF00397343

[47] S. J. Hanley, J. Giasson, J. F. Revol and D. G. Gray, "Atomic Force Microscopy of Cellulose Microfibrils: Comparison with Transmission Electron Microscopy," Polymer, Vol. 33, No. 21, 1992, pp. 4639-4642. doi:10.1016/0032-3861(92)90426-W

[48] N. H. Kim, W. Herth, R. Vuong and H. Chanzy, "The Cellulose System in the Cell Wall of Micrasterias," Journal of Structural Biology, Vol. 117, No. 3, 1996, pp. 195-203. doi:10.1006/jsbi.1996.0083

[49] S. J. Hanley, J. F. Revol, L. Godbout and D. G. Gray, "Atomic Force Microscopy and Transmission Electron Microscopy of Cellulose from Micrasterias denticulata; Evidence for a Chiral Helical Microfibril Twist," Cellulose, Vol. 4, No. 3, 1997, pp. 209-220. doi:10.1023/A:1018483722417

[50] T. Imai and J. Sugiyama, "Nanodomains of I-Alpha and I-Beta Cellulose in Algal Microfibrils," Macromolecules, Vol. 31, No. 18, 1998, pp. 6275-6279. doi:10.1021/ma980664h

[51] H. Yamamoto and F. Horii, "In Situ crystallization of Bacterial Cellulose I. Influences of Polymeric Additives, Stirring and Temperature on the Formation Celluloses $\mathrm{I}_{\alpha}$ and $\mathrm{I}_{\beta}$ as Revealed by Cross Polarization/Magic Angle Spinning (CP/MAS)13C NMR Spectroscopy,” Cellulose, Vol. 1, No. 1, 1994, pp. 57-66. doi:10.1007/BF00818798

[52] C. Tokoh, K. Takabe, M. Fujita and H. Saiki, "Cellulose Synthesized by Acetobacter xylinum in the Presence of Acetyl Glucomannan," Cellulose, Vol. 5, No. 4, 1998, pp. 249-261. doi:10.1023/A:1009211927183

[53] T. Koshizawa, "Investigation on Dissolving Pulp. XIV. Some Behavior of Wood Pulp and Cotton Linters in Phosphoric Acid," Bulletin of the Chemical Society of Japan, Vol. 31, No. 6, 1958, pp.705-708. doi:10.1246/bcsj.31.705

[54] T. Okano, S. Kuga, M. Wada, J. Araki and J. Ikuina, JP 98/151052, Nisshin Oil Mills Ltd., Japan, 1999.

[55] H. Ono, T. Matsui and I. Miyamato, WO98/JP5462, Japan, 1999.

[56] P. B. Filson and B. E. Dawson-Andoh, "Sono-Chemical Preparation of Cellulose Nanocrystals from Lignocellulose Derived Materials,” Bioresource Technology, Vol. 100, No. 7, 2009, pp. 2259-2264. doi:10.1016/j.biortech.2008.09.062

[57] J. Araki, M. Wada, S. Kuga and T. Okano, "Flow Prop- 
erties of Microcrystalline Cellulose Suspension Prepared by Acid Treatment of Native Cellulose," Colloids and Surfaces A: Physicochemical and Engineering Aspects, Vol. 142, No. 1, 1998, pp. 75-82. doi:10.1016/S0927-7757(98)00404-X

[58] J. F. Revol, H. Bradford, J. Giasson, R. H. Marchessault and D. G. Gray, "Helicoidal Self-Ordering of Cellulose Microfibrils in Aqueous Suspension,” International Journal of Biological Macromolecules, Vol. 14, No. 3, 1992, pp. 170-172. doi:10.1016/S0141-8130(05)80008-X

[59] M. Roman and W. T. Winter, "Effect of Sulfate Groups from Sulfuric Acid Hydrolysis on the Thermal Degradation Behaviour of Bacterial Cellulose,” Biomacromolecules, Vol. 5, No. 5, 2004, pp.1671-1677. doi:10.1021/bm034519+

[60] N. Wang, E. Ding and R. Cheng, “Thermal Degradation Behaviors of Spherical Cellulose Nanocrystals with Sulfate Groups,” Polymer, Vol. 48, No. 12, 2007, pp. 34863493. doi:10.1016/j.polymer.2007.03.062

[61] O. A. Battista and P. A. Smith, "Level-Off Degree of Polymerization Cellulose Products,” US Patent No. 2, 978, 446, 1961.

[62] O. A. Battista and P. A. Smith, "Crystallite Cellulosic Aggregates Prepared in an Acid Medium,” US Patent No. 3,141,875, 1964.

[63] O. A. Battista and J. J. Jr. Byrne, "Cellulose Crystallite Aggregates in Chromatographic Adsorption,” US Patent No. 3,179,587, 1965.

[64] X. M. Dong, J. F. Revol and D. G. Gray, "Effect of Microcrystallite Preparation Conditions on the Formation of Colloid Crystals of Cellulose," Cellulose, Vol. 5, No. 1, 1998, pp. 19-32. doi:10.1023/A:1009260511939

[65] J. Araki, M. Wada, S. Kuga and T. Okano, "Birefringent Glassy Phase of a Cellulose Microcrystal Suspension," Langmuir, Vol. 16, No. 6, 2000, pp. 2413-2415. doi:10.1021/la9911180

[66] Y. Habibi, A. Goffin, N. Schiltz, E. Duquesne, P. Dubois and A. Dufresne, "Bionanocomposites Based on Poly ( $\varepsilon$-caprolactone)-Grafted Cellulose Nanocrystals by RingOpening Polymerisation,” Journal of Materials Chemistry, Vol. 18, No. 41, 2008, pp. 5002-5010. doi:10.1039/b809212e

[67] Y. Habibi, L. Foulon, V. Aguié-Béghin, M. Molinari and R. Douillard, "Langmuir-Blodgett Films of Cellulose Nanocrystals: Preparation and Characterisation,” Journal of Colloid and Interface Science, Vol. 316, No. 2, 2007, pp. 388-397. doi:10.1016/j.jcis.2007.08.041

[68] X. Cao, Y. Chen, P. R. Chang, M. Stumborg and M. A. Huneault, "Green Composites Reinforced with Hemp Nanocrystals in Plasticized Starch,” Journal of Applied Polymer Science, Vol. 109, No. 6, 2008, pp. 3804-3810. doi:10.1002/app.28418

[69] X. Cao, Y. Chen, P. R. Chang, A. D. Muir and G. Falk, "Starch-Based Nanocomposites Reinforced with Flax Cellulose Nanocrystals,” Express Polymer Letters, Vol. 2, No. 7, 2008, pp. 502-510. doi:10.3144/expresspolymlett.2008.60
[70] X. Cao, H. Dong and C. M. Li, "New Nanocomposite Materials Reinforced with Flax Cellulose Nanocrystals in Waterborne Polyurethane,” Biomacromolecules, Vol. 8, No. 3, 2007, pp. 899-904. doi:10.1021/bm0610368

[71] A. Bendahou, Y. Habibi, H. Kaddami and A. Dufresne, "Physico-Chemical Characterization of Palm from Phoenix Dactylifera-L, Preparation of Cellulose Whiskers and Natural Rubber-Based Nanocomposites," Journal of Biobased Materials and Bioenergy, Vol. 3, No. 1, 2009, pp. 81-90. doi:10.1166/jbmb.2009.1011

[72] J. Araki, M. Wada, S. Kuga and T. Okano, "Influence of Surface Charge on Viscosity Behavior of Cellulose Microcrystal Suspension,” Journal of Wood Science, Vol. 45, No. 3, 1999, pp. 258-261. doi:10.1007/BF01177736

[73] M. Roohani, Y. Habibi, N. M. Belgacem, G. Ebrahim, A. N. Karimi and A. Dufresne, "Cellulose Whiskers Reinforced Polyvinyl Alcohol Copolymers Nanocomposites," European Polymer Journal, Vol. 44, No. 8, 2008, pp. 2489-2498. doi:10.1016/j.eurpolymj.2008.05.024

[74] X. Cao, Y. Habibi and L. A. Lucia, "One-Pot Polymerization, Surface Grafting, and Processing of Waterborne Polyurethane-Cellulose Nanocrystal Nanocomposites," Journal of Materials Chemistry, Vol. 19, No. 38, 2009, pp. 7137-7145. doi:10.1039/b910517d

[75] J. R. Capadona, K. Shanmuganathan, S. Trittschuh, S. Seidel, S. J. Rowan and C. Weder, "Polymer Nanocomposites with Nanowhiskers Isolated from Microcrystalline Cellulose,” Biomacromolecules, Vol. 10, No. 4, 2009, pp. 712-716. doi:10.1021/bm8010903

[76] D. Bondeson, I. Kvien and K. Oksman, "In Cellulose Nanocomposites: Processing, Characterization, and Properties,” In: K. Oksman and M. Sain, Eds., ACS Symposium Series 938, American Chemical Society, Washington DC, 2006.

[77] M. A. S. A. Samir, F. Alloin, M. Paillet and A. Dufresne, "Tangling Effect in Fibrillated Cellulose Reinforced Nanocomposites,” Macromolecules, Vol. 37, No. 11, 2004, pp. 4313-4316. doi:10.1021/ma035939u

[78] M. Grunert and W. T. Winter, "Nanocomposites of Cellulose Acetate Butyrate Reinforced with Cellulose Nanocrystals," Journal of Polymers and the Environment, Vol. 10, No. 1-2, 2002, pp. 27-30. doi:10.1023/A:1021065905986

[79] J. Araki and S. Kuga, "Effect of Trace Electrolyte on Liquid Crystal Type of Cellulose Microcrystals," Langmuir, Vol. 17, No. 15, 2001, pp. 4493-4496. doi:10.1021/la0102455

[80] A. Hirai, O. Inui, F. Horii and M. Tsuji, "Phase Separation Behavior in Aqueous Suspensions of Bacterial Cellulose Nanocrystals Prepared by Sulfuric Acid Treatment,” Langmuir, Vol. 25, No. 1, 2009, pp.497-502. doi:10.1021/la802947m

[81] M. N. Angles and A. Dufresne, "Plasticized Starch/Tuni cin Whiskers Nanocomposites: 1. Structural Analysis," Macromolecules, Vol. 33, No. 22, 2000, pp. 8344-8353. doi:10.1021/ma0008701

[82] H. Angelier, L. Choisnard, S. Molina-Boisseau, P. Ozil 
and A. Dufresne, "Optimization of the Preparation of Aqueous Suspensions of Waxy Maize Starch Nanocrystals Using a Response Surface Methodology,” Biomacromolecules, Vol. 5, No. 4, 2004, pp.1545-1550. doi:10.1021/bm049914u

[83] C. Xuerong and C. Yandan, "Method for Preparing Nanocrystal Cellulose I by Applying Acid Cation Exchange Resin,” CN101759807A, 2010.

[84] H. Ishikawa, S. Ide and C. Kawamata, "Manufacture of Microfibrillated Cellulose Fibers,” JP92-165820, 5, 1994.

[85] H. Shibuya and T. Hayashi, "Manufacture of Cellulose Nanofibers by Enzymatic Treatment and Cellulose Nanofibers Manufactured Thereby,” JP2006-337350, 13, 2008.

[86] H. Yano, N. Seki and T. Ishida, "Manufacture of Nanofibers and nanofibers manufactured thereby,” JP2007-2229, 17, 2008.

[87] M. Ankerfors, T. Lindstrom and G. Henriksson, "Method for Treating Chemical Pulp for Manufacturing Micro-Fibrillated," US20090221812, 2009.

[88] M. Vehvilaeinen, T. Kamppuri, M. Peltola, et al., "Process for Producing Microfibrillated Cellulose,” WO2011 004300A1, 2011.

[89] I. Heiskanen, K. Backfolk, M. Vehviläinen, et al., "Process for the Production of Microfibrillated Cellulose and Produced Microfibrillated Cellulose,” WO2011004284, 2011.

[90] G. Henriksson, A. Nut, H. Henriksson, B. Pettersson, J. Stahlberg, G. Johansson and G. Pettersson, "Endoglucanase 28 (Cel12a), A New Phanerochaete Chrysosporium Cellulase," European Journal of Biochemistry, Vol. 259, No. 1-2, 1999, pp. 88-95. doi:10.1046/j.1432-1327.1999.00011.x

[91] G. Henriksson, M. Christiernin and R. Agnemo, "Monocomponent Endoglucanase Treatment Increases the Reactivity of Softwood Sulfite Dissolving Pulp,” Journal of Industrial Microbiology and Biotechnology, Vol. 32, No. 5, 2005, pp. 211-214. doi:10.1007/s10295-005-0220-7

[92] E. R. Berghem and L. G. Pettersson, "Mechanism of Enzymatic Cellulose Degradation-Purification of A Cellulolytic Enzyme from Trichoderma-Viride Active on Highly Ordered Cellulose," European Journal of Biochemistry, Vol. 37, No. 1, 1973, pp. 21-30. doi:10.1111/j.1432-1033.1973.tb02952.x

[93] A. Lopez-Rubio, J. M. Lagaron, M. Ankerfors, T. Lindström, D. Nordqvist, A. Mattozzi and M. S. Hedenqvist, "Enhanced Film Forming and Film Properties of Amylopectin Using Micro-Fibrillated Cellulose," Carbohydrate Polymers, Vol. 68, No. 4, 2007, pp. 718-727. doi:10.1016/j.carbpol.2006.08.008

[94] A. J. Svagan, M. A. S. A. Samir and L. A. Berglund, "Biomimetic Polysaccharide Nanocomposites of High Cellulose Content and High Toughness," Biomacromolecules, Vol. 8, No. 8, 2007, pp. 2556-2563. doi:10.1021/bm0703160

[95] P. B. Filson, B. Dawson-Andoh and D. Schwegler-Berry, "Enzymatic-Mediated Production of Cellulose Nanocrystals from Recycled Pulp,” Green Chemistry, Vol. 11, No.

\section{1, 2009, pp. 1808-1814. doi:10.1039/b915746h}

[96] T. Saito and A. Isogai, "Introduction of Aldehyde Groups on Surfaces of Native Cellulose Fibers by TEMPO-Mediated Oxidation," Colloids and Surfaces A: Physicochemical and Engineering Aspects, Vol. 289, No.1-3, 2006, pp. 219-225. doi:10.1016/j.colsurfa.2006.04.038

[97] T. Saito, S. Kimura, Y. Nishiyama and A. Isogai, "Cellulose Nanofibers Prepared by TEMPO-Mediated Oxidation of Native Cellulose," Biomacromolecules, Vol. 8, No. 8, 2007, pp. 2485-2491. doi:10.1021/bm0703970

[98] T. Saito, M. Hirota, N. Tamura, S. Kimura, H. Fukuzumi, L. Heux and A. Isogai, "Individualization of Nano-Sized Plant Cellulose Fibrils by Direct Surface Carboxylation Using TEMPO Catalyst under Neutral Conditions," Biomacromolecules, Vol. 10, No. 7, 2009, pp. 1992-1996. doi:10.1021/bm900414t

[99] Y. Habibi and M. Vignon, "Optimization of Cellouronic Acid Synthesis by TEMPO-Mediated Oxidation of Cellulose III from Sugar Beet Pulp,” Cellulose, Vol. 15, No. 1, 2008, pp. 177-185. doi:10.1007/s10570-007-9179-z

[100] J. Araki, M. Wada and S. Kuga, "Steric Stabilization of A Cellulose Microcrystal Suspension by Poly(Ethylene Glycol) Grafting,” Langmuir, Vol. 17, No. 1, 2001, pp. 2127.

[101] J. Engelhard, S. Ficher, K. Hettrich, et al., "Nanoparticles of Slightly Oxidized Cellulose,” WO2009021688A1, 2009.

[102] S. Miyawaki, S. Katsukawa, H. Abe, et al., "Process for Producing Cellulose Nanofibers,” WO2010116826A1, 2010.

[103] S. Miyawaki, S. Katsukawa, H. Abe, et al., "Process for Producing Cellulose Nanofibers, Cellulose Oxidation Catalysts and Methods for Oxidizing Cellulose,” US2010 282422A1, 2010

[104] M. Frey and Y. L. Joo, "Cellulose Solution in Novel Solvent and Electrospinning Thereof,” US2005247236A1, 2005.

[105] M. H. F. Godinho, J. P. H. G. Canejo, J. P. M. R. Borges, et al., "Nanofibras Celulósicas Obtida por Electrospinning a Partir de Soluções Liquidas,” PT104094A, 2010.

[106] T. Christoforou and C. Doumanidis, "Biodegradable Cellulose Acetate Nanofiber Fabrication via Electrospinning,” Journal of Nanoscience and Nanotechnology, Vol. 10, No. 9, 2010, pp. 6226-6233. doi:10.1166/jnn.2010.2577

[107] A. N. Nakagaito and H. Yano, "Novel High-Strength Biocomposites Based on Microfibrillated Cellulose Having nanoorder-Unit Web-Like Network Structure," $A p$ plied Physics A: Materials Science and Processing, Vol. 80, No. 1, 2005, pp. 155-159. doi:10.1007/s00339-003-2225-2

[108] P. Stenstad, M. Andresen, B. S. Tanem and P. Stenius, "Chemical Surface Modifications of Microfibrillated Cellulose,” Cellulose, Vol. 15, No. 1, 2008, pp. 35-45. doi:10.1007/s10570-007-9143-y

[109] A. N. Nakagaito and H. Yano, “The Effect of Morpho- 
logical Changes from Pulp Fiber Towards Nano-Scale Fibrillated Cellulose on the Mechanical Properties of High-Strength Plant Fiber Based Composites," Applied Physics A: Materials Science and Processing, Vol. 78, No. 4, 2004, pp. 547-552. doi:10.1007/s00339-003-2453-5

[110] M. Shigematsu, "Fibrillar Cellulose and Its Production," JP2000017592A, 2000

[111] I. Hiroshyokota and O. Yoshiaki, "Homogenization of Microcrystalline Cellulose Suspension,” JP59120638A, 1984.

[112] T. Zimmermann, E. Pohler and T. Geiger, "Cellulose Fibrils for Polymer Reinforcement," Advanced Engineering Materials, Vol. 6, No. 9, 2004, pp. 754-761. doi:10.1002/adem.200400097

[113] T. Lindström, “Towards New Perspectives in Paper Chemistry,” Das Papier IPW, Vol. 10, 2007, pp. 32- 36.

[114] S. Beck, J. Bouchard and R. Berry, "Control of Nanocrystalline Cellulose Film Iridescence Wavelength,” US 20100279019, 2010.

[115] C. Peng, C. Wenshuai, H. Yunfei, et al., "Preparation Method of Homogenized Fine Nano-Cellulose Fiber," CN 101851295A, 2010.

[116] C. Peng, C. Wenshuai, L. Yixing, et al., "Method for Preparing Nanometer Cellulose Fiber through Combining Ultrasound and Highpressure Homogenization Treatment," CN101851801A, 2010.

[117] J. Paltakari, J. Laine, M. Österberg, et al., “A Method for Producing Modified Cellulose,” WO2010092239A1, 2010.

[118] P. A. C. Gane, J. Schoelkopf, D. Gantenbein, et al., "Process for the Production of Nano-Fibrillar Cellulose Gels," WO2010115785A1, 2010.

[119] M. Ankerfors and T. Lindstrom, "Method for Providing Nanocellulose Involving Modifying Cellulose Fibers," US20110036522A1, 2011.

[120] T. Taniguchi and K. Okamura, "New Films Produced from Microfibrillated Natural Fibres,” Polymer International, Vol. 47, No. 3, 1998, pp. 291-294, doi:10.1002/(SICI)1097-0126(199811)47:3<291::AID-PI $\underline{11>3.0 . \mathrm{CO} ; 2-1}$

[121] K. Abe, S. Iwamoto and H. Yano, "Obtaining Cellulose Nanofibers with a Uniform Width of 15 nm From Wood," Biomacromolecules, Vol. 8, No. 10, 2007, pp. 3276-3278 doi:10.1021/bm700624p

[122] S. Iwamoto, A. N. Nakagaito, H. Yano and M. Nogi, "Optically Transparent Composites Reinforced with Plant Fiber-Based Nanofibers," Applied Physics A: Materials Science and Processing, Vol. 81, No. 6, 2005, pp. 11091112. doi:10.1007/s00339-005-3316-Z

[123] S. Iwamoto, A. N. Nakagaito and H. Yano, "Nano-Fibrillation of Pulp Fibers for the Processing of Transparent Nanocomposites," Applied Physics A: Materials Science and Processing, Vol. 89, No. 2, 2007, pp. 461-466. doi:10.1007/s00339-007-4175-6

[124] A. Chakraborty, M. Sain and M. Kortschot, "Cellulose Microfibrils: A Novel Method of Preparation Using High Shear Refining and Cryocrushing," Holzforschung, Vol.
59, No. 1, 2005, pp. 102-107. doi:10.1515/HF.2005.016

[125]B. Wang and M. Sain, "Dispersion of Soybean StockBased Nanofiber in a Plastic Matrix,” Polymer International, Vol. 56, No. 4, 2007, pp. 538-546. doi:10.1002/pi.2167

[126] A. Bhatnagar and M. Sain, "Processing of Cellulose Nanofiberreinforced Composites,” Journal of Reinforced Plastics and Composites, Vol. 24, No. 12, 2005, pp. 12591268. doi:10.1177/0731684405049864

[127] M. M. de Souza Lima, J. T. Wong, M. Paillet, R. Borsali and R. Pecora, "Translational and Rotational Dynamics of Rodlike Cellulose Whiskers,” Langmuir, Vol. 19, No. 1, 2003, pp. 24-29. doi:10.1021/la020475z

[128] C. Rondeau-Mouro, B. Bouchet, B. Pontoire, P. Robert, J. Mazoyer and A. Buleon, "Structural Features and Potential Texturizing Properties of Lemon and Maize Cellulose Microfibrils," Carbohydrate Polymers, Vol. 53, 2003, pp. 241- 252. doi:10.1016/S0144-8617(03)00069-9

[129] L. Mott, L. Groom and S. Shaler, "Mechanical Properties of Individual Southern Pine Fibers. Part II. Comparison of Earlywood and Latewood Fibers with Respect to Tree Height and Juvenility,” Wood and Fiber Science, Vol. 34, No. 2, 2002, pp. 221-237.

[130] S. J. Eichhorn, J. Sirichaisit and R. J. Young, "Deformation Mechanisms in Cellulose Fibres, Paper and Wood," Journal of Materials Science, Vol. 36, No. 13, 2001, pp. 3129-3135. doi:10.1023/A:1017969916020

[131] S. J. Eichhorn and R. J. Young, "The Young's Modulus of a Microcrystalline Cellulose,” Cellulose, Vol. 8, No. 3, 2001, pp. 197-207. doi:10.1023/A:1013181804540

[132] R. R. Lahiji, X. Xu, R. Reifenberger, A. Raman, A. Rudie and R. J. Moon, "Atomic Force Microscopy Characterization of Cellulose Nanocrystals,” Langmuir, 2010, Vol. 26, No. 6, pp. 4480-4488. doi:10.1021/la903111j

[133] R. Rusli and S. J. Eichhorn, "Determination of the Stiffness of Cellulose Nanowhiskers and the Fiber-Matrix Interface in a Nanocomposite Using Raman Spectroscopy," Applied Physics Letters, Vol. 93, No. 3, 2008, Article ID: 033111. doi:10.1063/1.2963491

[134] A. Sturcova, G. R. Davies and S. J. Eichhorn, "Elastic Modulus and Stress-Transfer Properties of Tunicate Cellulose Whiskers,” Biomacromolecules, Vol. 6, No. 2, 2005, pp. 1055-1061. doi:10.1021/bm049291k

[135] Y. C. Hsieh, H. Yano, M. Nogi and S. J. Eichhorn, “An Estimation of the Young's Modulus of Bacterial Cellulose Filaments," Cellulose, Vol. 15, No. 4, 2008, pp. 507513. doi:10.1007/s10570-008-9206-8

[136] T. Nishino, I. Matsuda and K. Hirao, “All-Cellulose Composite,” Macromolecules, Vol. 37, No. 20, 2004, pp. 7683-7687. doi:10.1021/ma049300h

[137] H. Yano, J. Sugiyama, A. N. Nakagaito, M. Nogi, T. Matsuura, M. Hikita and K. Handa, "Optically Transparent Composites Reinforced with Networks of Bacterial Nanofibers," Advanced Materials, Vol. 17, No. 2, 2005, pp. 153-155. doi:10.1002/adma.200400597

[138] A. N. Nakagaito, M. Nogi and H. Yano, "Displays from Transparent Films of Natural Nanofibers,” MRS Bulletin, 
Vol. 35, No. 3, 2010, pp. 214-218.

doi:10.1557/mrs2010.654

[139] E. Lasseuguette, D. Roux and Y. Nishiyama, "Rheological Properties of Microfibrillar Suspension of TEMPOOxidized Pulp," Cellulose, Vol. 15, No. 3, 2008, pp. 425433. doi:10.1007/s10570-007-9184-2

[140] S. Spoljaric, A. Genovese and R. A. Shanks, "Polypropylene-Microcrystalline Cellulose Composites with Enhanced Compatibility and Properties," Composites Part A: Applied Science and Manufacturing, Vol. 40, No. 6-7, 2009, pp. 791-799. doi:10.1016/j.compositesa.2009.03.011

[141] S. Padalkar, J. R. Capadona, S. J. Rowan, C. Weder, Y. H. Won, L. A. Stanciu and R. J. Moon, "Natural Biopolymers: Novel Templates for the Synthesis of Nanostructures,” Langmuir, Vol. 26, No. 11, 2010, pp. 8497-8502. doi:10.1021/la904439p

[142] L. Heux, G. Chauve and C. Bonini, "Nonflocculating and Chiral-Nematic Self-Ordering of Cellulose Microcrystals Suspensions in Nonpolar Solvents," Langmuir, Vol. 16, No. 21, 2000, pp.8210-8212. doi:10.1021/la9913957

[143] L. Heux, and C. Bonini, "Microfibrillated and/or Micrcroystalline Dispersion, in Particular of Cellulose, in an Organic Solvent,” International Patent WO 2000/077088, 2000.

[144] E. D. Cranston and D. G. Gray, "Morphological and Optical Characterization of Polyelectrolyte Multilayers Incorporating Nanocrystalline Cellulose,” Biomacromolecules, Vol. 7, No. 9, 2006, pp. 2522-2530. doi:10.1021/bm0602886

[145] C. Goussé, H. Chanzy, G. Excoffier, L. Soubeyrand and E. Fleury, "Stable Suspensions of Partially Silylated Cellulose Whiskers Dispersed in Organic Solvents,” Polymer, Vol. 43, No. 9, 2002, pp. 2645-2651. doi:10.1016/S0032-3861(02)00051-4

[146] Y. Habibi, H. Chanzy and M. Vignon, “TEMPO-Mediated Surface Oxidation of Cellulose Whiskers," Cellulose, Vol. 13, No. 6, pp. 679-687. doi:10.1007/s10570-006-9075-y

[147] M. Hasani, E. D. Cranston, G. Westman and D. G. Gray, "Cationic Surface Functionalisation of Cellulose Nanocrystals,” Soft Matter, Vol. 4, No. 11, 2008, pp. 2238-2244. doi:10.1039/b806789a

[148] B. Braun and J. R. Dorgan, “Single-Step Method for the Isolation and Surface Functionalisation of Cellulosic Nanowhiskers," Biomacromolecules, Vol. 10, No. 2, 2009, pp. 334-341. doi:10.1021/bm8011117

[149] G. Morandi, L. Heath and W. Thielemans, "Cellulose Nanocrystals Grafted With Polystyrene Chains through Surface-Initiated Atom Transfer Radical Polymerisation (SI-ATRP)," Langmuir, Vol. 25, No. 14, 2009, pp. 82808286. doi:10.1021/la900452a

[150] J. Sassi and H. Chanzy, "Ultrastructural Aspects of the Acetylation of Cellulose,” Cellulose, Vol. 2, No. 2, 1995, pp. 111-127. doi:10.1007/BF00816384

[151] H. Yuan, Y. Nishiyama, M. Wada and S. Kuga, "Surface Acylation of Cellulose Whiskers by Drying Aqueous
Emulsion,” Biomacromolecules, Vol. 7, No. 3, 2006, pp. 696-700. doi:10.1021/bm050828j

[152] N. S. Cetin, P. Tingaut, N. Özmen, N. Henry, D. Harper, M. Dadmun and G. Sèbe, "Acetylation of Cellulose Nanowhiskers With Vinyl Acetate under Moderate Conditions," Macromolecular Bioscience, Vol. 9, No. 10, 2009, pp. 997-1003. doi:10.1002/mabi.200900073

[153] S. Berlioz, S. Molina-Boisseau, Y. Nishiyama and L. Heux, "Gas-Phase Surface Esterification of Cellulose Microfibrils and Whiskers," Biomacromolecules, Vol. 10, No. 8, 2009, pp. 2144-2151. doi:10.1021/bm900319k

[154] A. de Menezes Jr., G. Siqueira, A. A. S. Curvelo and A. Dufresne, "Extrusion and Characterisation of Functionalised Cellulose Whiskers Reinforced Polyethylene Nanocomposites,” Polymer, Vol. 50, No. 19, 2009, pp. 45524563. doi:10.1016/j.polymer.2009.07.038

[155] S. P. Dong, S. P. and M. Roman, "Fluorescently Labeled Cellulose Nanocrystals for Bioimaging Applications," Journal of the American Chemical Society, Vol. 129, No. 45, 2007, pp.13810-13811. doi:10.1021/ja0761961

[156] J. Yi, Q. Xu, X. Zhang and H. Zhang, "Chiral-Nematic Self-Ordering of Rodlike Cellulose Nanocrystals Grafted with Poly(Styrene) in Both Thermotropic and Lyotropic States," Polymer, Vol. 49, No. 20, 2008, pp. 4406-4412. doi:10.1016/j.polymer.2008.08.008

[157] H. Lönnberg, L. Fogelström, M. A. S. A. Samir, L. Berglund, E. Malmström and A. Hult, "Surface Grafting of Microfibrillated Cellulose with Poly( $\varepsilon$-Caprolactone)-Synthesis and Characterization,” European Polymer Journal, Vol. 44, No. 9, 2008, pp. 2991-2997. doi:10.1016/j.eurpolymj.2008.06.023

[158] W. Thielemans, M. N. Belgacem and A. Dufresne, "Starch Nanocrystals with Large Chain Surface Modifications," Langmuir, Vol. 22, No. 10, 2006, pp. 4804-4810. doi:10.1021/la053394m

[159] F. Azzam, L. Heux, J. L. Putaux and B. Jean, "Preparation by Grafting onto Characterisation, and Properties of Thermally Responsive Polymer-Decorated Cellulose Nanocrystals,” Biomacromolecules, Vol. 11, No. 12, 2010, pp. 3652-3659. doi:10.1021/bm101106c

[160] N. Ljungberg, C. Bonini, F. Bortolussi, C. Boisson, L. Heux and J. Y. Cavaillé, "New Nanocomposite Materials Reinforced with Cellulose Whiskers in Atactic Polypropylene: Effect of Surface and Dispersion Characteristics," Biomacromolecules, Vol. 6, No. 5, 2005, pp. 2732-2739. doi:10.1021/bm050222v

[161] A. P. Mangalam, J. Simonsen and A. S. Benight, "Cellulose/DNA Hybrid Nanomaterials,” Biomacromolecules, Vol. 10, No. 3, 2009, pp. 497-504. doi:10.1021/bm800925x

[162] J. Wang and K. Matyjaszewski, “Controlled/Living Radical Polymerisation. Atom Transfer Radical Polymerisation in the Presence of Transition-Metal Complexes," Journal of the American Chemical Society, Vol. 117, No. 20, 1995, pp. 5614-5615. doi:10.1021/ja00125a035

[163] J. Yi, Q. Xu, X. Zhang and H. Zhang, “TemperatureInduced Chiral Nematic Phase Changes of Suspensions of Poly(N,N-Dimethylaminoethyl Methacrylate)-Grafted Cel- 
lulose Nanocrystals,” Cellulose, Vol. 16, No. 6, pp. 989997. doi:10.1007/s10570-009-9350-9

[164] G. Chen, A. Dufresne, J. Huang and P. R. Chang, “A Novel Thermoformable Bionanocomposite Based on Cellulose Nanocrystal-Graft-Poly( $\varepsilon$-caprolactone)," Macromolecular Materials and Engineering, Vol. 294, No. 1, 2009, pp. 59-67. doi:10.1002/mame.200800261

[165] N. Lin, G. Chen, J. Huang, A. Dufresne and P. R. Chang, "Effects of Polymer-Grafted Natural Nanocrystals on the Structure and Mechanical Properties of Poly(Lactic Acid): A Case of Cellulose Whisker-Graft-Polycaprolactone," Journal of Applied Polymer Science, Vol. 113, No. 5, 2009, pp. 3417-3425. doi:10.1002/app.30308

[166] S. J. Eichhorn, A. Dufresne, M. Aranguren, N. E. Marcovich, J. R. Capadona, S. J. Rowan, C. Weder, W. Thielemans, M. Roman, S. Renneckar, W. Gindl, S. Veigel, J. Keckes, H. Yano, K. Abe, M. Nogi, A. N. Nakagaito, A. Mangalam, J. Simonsen, A. S. Benight, A. Bismarck, L. A. Berglund and T. Peijs, "Review: Current International Research into Cellulose Nanofibres and Nanocomposites,” Journal of Materials Science, Vol. 45, No. 1, 2010, pp. 1-33. doi:10.1007/s10853-009-3874-0

[167] M. A. S. A. Samir, F. Alloin and A. Dufresne, "Review of Recent Research into Cellulosic Whiskers, Their Properties and Their Application in Nanocomposite Field," Biomacromolecules, Vol. 6, No. 2, 2005, pp. 612-626. doi:10.1021/bm0493685

[168] S. Kamel, "Nanotechnology and Its Applications in Lignocellulosic Composites, a Mini Review," eXPRESS Polymer Letter, Vol. 1, No. 9, 2007, pp. 546-575.

[169] W. K. Wan and L. Millon, "Poly (Vinyl Alcohol)-Bacterial Cellulose Nanocomposite,” US200900289, 2009.

[170] K. Tetsuo, "Material Comprising Polylactic Acid and Cellulose Fiber,” WO2007136086A1, 2007.

[171] J. M. Catchmark, D. M. Mears, J. Siggins, et al., "Composites Containing Polypeptides Attached to Polysaccharides and Molecules,” WO2011047047A2, 2011.

[172] N. Kotov, B. S. Shim and P. Podsiadlo, "Layer-by-Layer Assemblies Having Preferential Alignment of Deposited Axially Anisotropic Species and Methods for Preparation and Use Thereof,” US20100098902A1, 2010.

[173] K. Oksman, D. Bondeson and P. Syre, "Nanocomposites Based on Cellulose Whiskers and Cellulose Plastics," US 20080108772A1, 2008.

[174] C. H. Hong and S. Han, "Nylon-4 Composite,” US 2011 0086948A1, 2011.

[175] Y. Oku, "Flexible Substrate and Manufacturing Method Thereof,” US20090202843A1, 2009.

[176] C. Weder, J. Capadona and O. Van Den Berg, "Self-Assembled Nanofibers Templates,” US2008242765A1, 2008.

[177] I. Kvien, B. S. Tanem and K. Oksman, "Characterization of Cellulose Whiskers and Their Nanocomposites by Atomic Force and Electron Microscopy," Biomacromolecules, Vol. 6, No. 6, 2005, pp. 3160-3165. doi:10.1021/bm050479t

[178] M. A. S. A. Samir, F. Alloin, J. Y. Sanchez, N. El Kissi and A. Dufresne, "Preparation of Cellulose Whiskers Reinforced Nanocomposites from an Organic Medium Suspension," Macromolecules, Vol. 37, No. 4, 2004, pp. 1386-1393. doi:10.1021/ma030532a

[179] O. Van den Berg, J. R. Capadona and C. Weder, "Preparation of Homogeneous Dispersions of Tunicate Cellulose Whiskers in Organic Solvents," Biomacromolecules, Vol. 8, No. 4, 2007, pp.1353-1357. doi:10.1021/bm061104q

[180] D. Viet, S. Beck-Candanedo and D. G. Gray, "Dispersion of Cellulose Nanocrystals in Polar Organic Solvents," Cellulose, Vol. 14, No. 2, 2007, pp.109-113. doi:10.1007/s10570-006-9093-9

[181] J. R. Capadona, O. Van Den Berg, L. A. Capadona, M. Schroeter, S. J. Rowan, D. J. Tyler and C. Weder, “A Versatile Approach for the Processing of Polymer Nanocomposites with Self-Assembled Nanofibre Templates," Nature Nanotechnology, Vol. 2, No. 12, 2007, pp. 765769. doi:10.1038/nnano.2007.379

[182] O. J. Rojas, G. A. Montero and Y. Habibi, "Electrospun Nanocomposites from Polystyrene Loaded with Cellulose Nanowhiskers,” Journal of Applied Polymer Science, Vol. 113, No. 2, 2009, pp. 927-935. doi:10.1002/app.30011

[183] J. O. Zoppe, M. S. Peresin, Y. Habibi, R. A. Venditti and O. J. Rojas, "Reinforcing Poly( $\varepsilon$-caprolactone) Nanofibers With Cellulose Nanocrystals," ACS Applied Materials Interfaces, Vol. 1, No. 9, 2009, pp. 1996-2004. doi:10.1021/am9003705

[184] W. I. Park, M. Kang, H. S. Kim and H. J. Jin, "Electrospinning of Poly(Ethylene Oxide) with Bacterial Cellulose Whiskers,” Macromolecular Symposia, Vol. 249-250, No. 1, 2007, pp. 289-294. doi:10.1002/masy.200750347

[185] W. L. E. Magalhäes, X. Cao and L. A. Lucia, “Cellulose Nanocrystals/Cellulose Core-in-Shell Nanocomposite Assemblies," Langmuir, Vol. 25, No. 22, 2009, pp. 13250 13257. doi:10.1021/la901928j

[186] M. Schroers, A. Kokil and C. Weder, "Solid Polymer Electrolytes Based on Nanocomposites of Ethylene Oxide-Epichlorohydrin Copolymers and Cellulose Whiskers,” Journal of Applied Polymer Science, Vol. 93, No. 6, 2004, pp. 2883-2888. doi:10.1002/app.20870

[187] K. Oksman, A. P. Mathew, D. Bondeson and I. Kvien, "Manufacturing Process of Cellulose Whiskers/Polylactic Acid Nanocomposites," Composites Science and Technology, Vol. 66, No. 15, 2006, 2776-2784. doi:10.1016/j.compscitech.2006.03.002

[188] D. Bondeson and K. Oksman, "Polylactic Acid/Cellulose Whisker Nanocomposites Modified by Polyvinyl Alcohol,” Composites Science and Technology, Vol. 38, No. 12, 2007, pp. 2486-2492. doi:10.1016/j.compositesa.2007.08.001

[189] S. Iwamoto, K. Abe and H. Yano, “The Effect of Hemicelluloses on Wood Pulp Nanofibrillation and Nanofiber Network Characteristics,” Biomacromolecules, Vol. 9, No. 3, 2008, pp. 1022-1026. doi:10.1021/bm701157n

[190] Y. Shimazaki, Y. Miyazaki, Y. Takezawa, M. Nogi, K. 
Abe, S. Ifuku and H. Yano, "Excellent Thermal Conductivity of Transparent Cellulose Nanofiber/Epoxy Resin Nanocomposites," Biomacromolecules, Vol. 8, No. 9, 2007, pp. 2976-2978. doi:10.1021/bm7004998

[191] M. Nogi, K. Handa, A. N. Nakagaito and H. Yano, "Optically Transparent Bionanofiber Composites with Low Sensitivity to Refractive Index of the Polymer Matrix," $A p$ plied Physics Letter, Vol. 87, No. 24, 2005, pp. 243110243112. doi:10.1063/1.2146056

[192] A. Nakagaito and H. Yano, "Toughness Enhancement of Cellulose Nanocomposites by Alkali Treatment of the Reinforcing Cellulose Nanofibers,” Cellulose, Vol. 15, No. 2, 2008, pp. 323-331. doi:10.1007/s10570-007-9168-2

[193] M. Özgür Seydibeyoglu and K. Oksman, "Novel Nanocomposites Based on Polyurethane and Micro Fibrillated Cellulose," Composites Science and Technology, Vol. 68, No. 3-4, 2008, pp. 908-914. doi:10.1016/j.compscitech.2007.08.008

[194] M. Henriksson, L. A. Berglund, P. Isaksson, T. Lindstrom and T. Nishino, "Cellulose Nanopaper Structures of High Toughness,” Biomacromolecules, Vol. 9, No. 6, 2008, pp. 1579-1585. doi:10.1021/bm800038n

[195] A. N. Nakagaito and H. Yano, "The Effect of Fiber Content on the Mechanical and Thermal Expansion Properties of Biocomposites Based on Microfibrillated Cellulose,” Cellulose, Vol. 15, No. 4, 2008, pp.555-559. doi:10.1007/s10570-008-9212-X

[196] M. Nogi, S. Ifuku, K. Abe, K. Handa, A. N. Nakagaito and H. Yano, "Fiber-Content Dependency of the Optical Transparency and Thermal Expansion of Bacterial Nanofiber Reinforced Composites," Applied Physics Letter, Vol. 88, No. 13, 2006, pp. 133121-133124.

[197] P. Podsiadlo, S. Choi, B. Shim, J. Lee, M. Cuddihy and N. A. Kotov, "Molecularly Engineered Nanocomposites: Layer-By-Layer Assembly of Cellulose Nanocrystals," Biomacromolecules, Vol. 6, No. 6, 2005, pp. 2914-2918. doi:10.1021/bm050333u

[198] B. Jean, F. Dubreuil, L. Heux and F. Cousin, "Structural Details of Cellulose Nanocrystals/Polyelectrolytes Multilayers Probed by Neutron Reflectivity and AFM," Langmuir, Vol. 24, No. 7, 2008, pp.3452-3458. doi:10.1021/la703045f

[199] E. D. Cranston and D. G. Gray, "Formation of CelluloseBased Electrostatic Layer-By-Layer Films in a Magnetic Field," Science and Technology of Advanced Materials, Vol. 7, No. 4, 2006, pp. 319-321. doi:10.1016/j.stam.2006.02.007

[200] E. D. Cranston and D. G. Gray, "Birefringence in SpinCoated Films Containing Cellulose Nanocrystals,” Colloids and Surfaces A: Physicochemical and Engineering Aspects, Vol. 325, No. 1-2, 2008, pp. 44-51. doi:10.1016/j.colsurfa.2008.04.042

[201] S. Kalia, A. Dufresne, B. M. Cherian, B. S. Kaith, L. Averous, J. Njuguna and E. Nassiopoulos, "CelluloseBased Bio- and Nanocomposites: A Review," International Journal of Polymer Science, Vol. 2011, 2011, pp. 1-35. doi:10.1155/2011/837875
[202] R. J. Moon, A. Martini, J. Nairn, J. Simonsen and Jeff Youngblood, "Cellulose Nanomaterials Review: Structure, Properties and Nanocomposites," Chemical Society Reviews, Vol. 40, No. 7, 2011, pp. 3941-3994. doi:10.1039/c0cs00108b

[203] J. D. Fontana, A. M. de Souza, C. K. Fontana, et al., "Acetobacter Cellulose Pellicle as a Temporary Skin Substitute," Applied Biochemistry and Biotechnology, Vol. 24-25, No. 1, 1990, pp: 253-264. doi:10.1007/BF02920250

[204] F. C. Tournilhac and R. Lorant, “Oil-in-Water Emulsion Composition Containing Cellulose Fibrils and Cosmetic Use Thereof,” EP1057477A1, 2000.

[205] L. R. Mello, Y. Feltrin, R. Selbach, G. Macedo Jr., C. Spautz and L. J. Haas, "Use of Lyophilized Cellulose in Peripheral Nerve Lesions with Loss of Substance," $A r$ quivos de Neuro-Psiquiatria, Vol. 59, No. 2B, 2001, pp. 372-379. doi:10.1590/S0004-282X2001000300012

[206] D. Klemm, D. Schumann, U. Udhardt and S. Marsch, "Bacterial Synthesized Cellulose-Artificial Blood Vessels for Microsurgery," Progress in Polymer Science, Vol. 26, 2001, pp.1561-1603.doi:10.1016/S0079-6700(01)00021-1

[207] M. A. Croce, C. Silvestri, D. Guerra, et al., "Adhesion and Proliferation of Human Dermal Fibroblasts on Collagen Matrix,” Journal of Biomaterials Applications, Vol. 18, No. 3, 2004, pp. 209-222. doi: $10.1177 / 0885328204039692$

[208] S. W. Negrao, R. R. L. Bueno, E. E. Guérios, et al., “A Eficacia do Stent Recoberto com Celulose Biossint'etica Comparado ao Stent Convencional em Angioplastia em Coelhos," Revista Brasileira de Cardiologia Invasiva, Vol. 14, 2006, pp.10-19.

[209] W. K. Czaja, D. J. Young, M. Kawecki and R. M. Brown "The Future Prospects of Microbial Cellulose in Biomedical Applications,” Biomacromolecules, Vol. 8, No. 1, 2007, pp. 1-12. doi:10.1021/bm060620d

[210] R. Kozlowski, B. Laszkiewic, P. Kulpinski, et al., "Method of Manufacturing Silver Nanoparticles, Cellulosic Fibers and Nanofibers Containing Silver Nanoparticles, Use of Silver Nanoparticles to the Manufacture of Cellulosic Fibers and Nanofibers,” WO2008100163A1, 2008.

[211] C. Narayana, "Nanoparticle Composition, Useful for Manufacturing Antibacterial Medicament, Which Is Useful in e.g. Medical Applications e.g. Wound Dressing, Comprises Cellulose Nanofibers Embedded with Nanosized Material e.g. Silver,” WO2009063508A2, 2009.

[212] M. P. Laborie and E. Brown, "Method of in Situ Bioproduction and Composition of Bacterial Cellulose Nanocomposites,” US2009192264A1, 2009.

[213] C. Narayana, "Nanoparticle Composition and Process Thereof,” US2010233245A1, 2010.

[214] B. Chu, B. S. Hsiao and H. Ma "High Flux High Efficiency Nanofiber Membranes and Methods of Production Thereof,” WO2010042647A2, 2010.

[215] E. Andersen "Skin Care Compositions for the Delivery of Agents,” WO2010115426A1, 2010.

[216] W. A. W. I. Thielemans and R. Davies, “Cellulose Nano- 
particle Aerogels, Hydrogels and Organogels,” WO2011 030170A1, 2011.

[217] B. Chu, B. S. Hsiao and H. Ma, "High Flux High Efficiency Nanofiber Membranes and Methods of Production thereof,” WO2010042647A2, 2010.

[218] B. Chu, B. Hsiao and H. Ma, "High Flux Fluid Separation Membranes Comprising a Cellulose or Cellulose Derivative Layer,” WO2009025900A2, 2009.

[219] E. E. Koslow, "Microporous Filter Media, Filtration Systems Containing Same, and Methods of Making and Using," US2003205530A1, 2003.

[220] D. Klemm, F. Kramer, S. Moritz, et al., "Nanocelluloses: A New Family of Natural-Based Materials," Angewandte Chemie International Edition, Vol. 50, No. 24, 2011, pp. 5438-5466. doi:10.1002/anie.201001273

[221] N. Bordeanu, C. Eyholzer and T. N. N. Zummerma. "Surface Modified Cellulose Nanofibers,” WO2010066905A1, 2010.

[222] M. M. Sain and A. R. Bhatnaga, "Manufacturing Process of Cellulose Nanofibers from Renewable Feed Stocks," US2008146701A1, 2008.

[223] A. Ogino, Y. A. Midorikaw, A. Chatani, et al., "Paper for Recording of Information and Processed Paper," WO 2011001706A1, 2011.

[224] M. H. F. Godinho, J. P. B. M. Ribeiro, S. Kundu, et al., "Difusor Óptico Baseado em Nanofibras de Celulose e Cristais Líquidos Controlado por um Campo Externo,” PT104122A, 2010.

[225] Y. Oku, "Flexible Substrate and Manufacturing Method Thereof,” US2009202843A1, 2009.

[226] S. Rousseau and B. Tolnai "Method of Manufacturing Nano-Crystalline Cellulose Film,” US2010124651A1, 2010.

[227] S. Rebouillat, M. Escoubes, R. Gauthier and A. Vigier, "Thermally Induced Changes in Kevlar ${ }^{\circledR}$ Fibre Surface Evidenced by Inverse Gas Chromatography,” Polymer, Vol. 36, 1995, pp. 4521-4523. doi:10.1016/0032-3861(95)96863-4

[228] S. Rebouillat, M. Escoubes, R. Gauthier and A. Vigier, "Surface Energy Mapping of Kevlar ${ }^{\circledR}$ Fibers by Inverse Gas Chromatography," Journal of Applied Polymer Science, Vol. 58, No. 8, 1995, pp. 1305-1315. doi:10.1002/app.1995.070580812

[229] S. Rebouillat, J. B. Donnet, H. Guo and T. K. Wang, "Surface Energy Mapping of Kevlar ${ }^{\circledR}$ Fibers by Inverse Gas Chromatography,” Journal of Applied Polymer Science, Vol. 67, No. 3, 1998, pp. 487-500. doi:10.1002/(SICI)1097-4628(19980118)67:3<487::AIDAPP12>3.0.CO;2-T

[230] S. Rebouillat, J. B. Donnet and T. K. Wang, "Surface Microstructure of a Kevlar ${ }^{\circledR}$ Aramid Fibre Studied by Direct Atomic Force Microscopy,” Polymer, Vol. 38, No. 9, 1997, pp. 2245-2249. doi:10.1016/S0032-3861(96)00768-9

[231] S. Rebouillat, J. C. M. Peng and J. B. Donnet, “Surface Structure of Kevlar ${ }^{\circledR}$ Fiber Studied by Atomic Force Microscopy and Inverse Gas Chromatography,” Polymer,
Vol. 40, No. 26, 1999, pp. 7341-7350.

doi:10.1016/S0032-3861(99)00040-3

[232] S. Rebouillat, M. Escoubes and R. Gauthier, "Interactions of Kevlar ${ }^{\circledR}$ Fibers with Selected Model Compounds: Water Sorption and Dynamic Mechanical Properties of Fiber/Matrix Samples," Journal of Adhesion Science and Technology, Vol. 10, No. 7, 1996, pp. 635-650. doi:10.1163/156856196X00689

[233] S. Rebouillat, "Tribological Properties of Woven ParaAramid Fabrics and Their Constituent Yarns," Journal of Materials Science, Vol. 33, No. 13, 1998, pp. 3293-3301. doi:10.1023/A:1013225027778

[234] S. Rebouillat, “Aramids,” In: J. W. S. Hearle, Ed., High Performance Fibres, Woodhead Publishing Limited, Sawston, 2001, pp. 23-61.

[235] S. Rebouillat, et al., Eds., “Carbon Fibers,” Marcel Deckert, 1998.

[236] S. Rebouillat and M. E. G. Lyons, "Measuring the Electrical Conductivity of Single Fibres," International Journal of Electrochemical Science, Vol. 6, No. 11, 2011, pp. 5731-5740

[237] M. E. G. Lyons and S. Rebouillat, "Paving the Way to the Integration of Smart Nanostructures. Part 1: Nanotethering and Nanowiring via Material Nanoengineering and Electrochemical Identification,” International Journal of Electrochemical Science, Vol. 4, 2009, pp. 481-515.

[238] S. Rebouillat, M. E. G. Lyons, B. M. P. Doyle and L. Richard, "Paving the Way to the Integration of Smart Nanostructures: Part II: Nanostructured Microdispersed Hydrated Metal Oxides for Electrochemical Energy Conversion and Storage Applications," International Journal of Electrochemical Science, Vol. 6, 2011, pp. 5830-5917

[239] S. Rebouillat, B. Steffenino and B. Letellier, "Hydrodynamics of High Speed Fibre Impregnation," Chemical Engineering Science, Vol. 55, No. 1, 2000, pp. 15-24. doi:10.1016/S0009-2509(99)00186-4

[240] S. Rebouillat, B. Steffenino and B. Salvador, "Hydrodynamics of High-Speed Fibre Impregnation: The Fluid Layer Formation from the Meniscus Region," Chemical Engineering Science, Vol. 57, No. 18, 2002, pp. 39533966. doi:10.1016/S0009-2509(02)00309-3

[241] S. Rebouillat, B. Letellier and B. Steffenino, "Wettability of Single Fibres-Beyond the Contact Angle Approach," International Journal of Adhesion and Adhesives, Vol. 19, No. 4, 1999, pp. 303-314.

[242] S. Rebouillat, "Tribological Properties of Woven ParaAramid Fabrics and Their Constituent Yarns,” Journal of Materials Science, Vol. 33, No. 13, 1998. pp. 3293-3301.

[243] S. Rebouillat, M. Escoubes and R. Gauthier, "Interactions of Kevlar ${ }^{\circledR}$ Fibers with Selected Model Compounds: Water Sorption and Dynamic Mechanical Properties of Fiber/Matrix Samples,” International Journal of Adhesion and Adhesives, Vol. 10, No. 7, 1996, pp. 635-650 doi:10.1163/156856196X00689

[244] S. Rebouillat, D. Liksonov and A. Courgey, "New Experimental Device to Test the Dynamic Behavior of Fiber Assemblies and Fibrous Composite Structures with a Fo- 
cus on Larger Industrial-Scale-Like Samples,” Journal of Applied Polymer Science, Vol. 123, No. 3, 2012. pp. 17081717. doi:10.1002/app.34626

[245] S. Rebouillat, B. Steffenino and A. Miret-Casas, “Aramid, Steel, and Glass: Characterization via Cut Performance Testing, of Composite Knitted Fabrics and Their Constituent Yarns, with a Review of the Art," Journal of Ma- terials Science, Vol. 45, No. 19, 2010, pp. 5378-5392. doi:10.1007/s10853-010-4590-5

[246] D. A. Buttry, J. C. M. Peng, J.-B. Donnet and S. Rebouillat, "Immobilization of Amines at Carbon Fiber Surfaces,” Carbon, Vol. 37, No. 12, 1999, pp. 1929-1940. doi:10.1016/S0008-6223(99)00064-0 